\title{
Prenatal Development of Retinal Ganglion Cell Axons: Segregation into Eye-Specific Layers Within the Cat's Lateral Geniculate Nucleus
}

\author{
David W. Sretavan and Carla J. Shatz \\ Department of Neurobiology, Stanford University School of Medicine, Stanford, California 94305
}

The morphological changes in individual retinal ganglion cell axons associated with the formation of the eye-specific layers in the dorsal lateral geniculate nucleus (LGN) were studied during the prenatal development of the cat's visual system. Previous work has shown that the pattern of segregated eye inputs found in the adult arises from an immature state in which inputs from the two eyes are intermixed within the nucleus (Shatz, 1983). Here, this developmental process is examined at its fundamental unit of connectivity - the individual retinal ganglion cell axon. To do so, an in vitro method was used to label fetal cat optic tract axons with HRP at various times during development between embryonic day 38 (E38) and postnatal day 2 (P2) (gestation $=65 \mathrm{~d})$. The results presented here are based on reconstructions of 172 axons.

During the initial period of intermixing (E38-43), axons are relatively simple in morphology. Many axons studied at the earliest ages (E38) end in growth cones and have very few branches along the main axon trunk as they traverse the nucleus. By E43, the number of side branches given off along the main axon trunk has increased and most axons also have a simple terminal arbor. Over the next 2 weeks (E43-55), the majority of axons are studded with side branches and the terminal arbor is well defined. Then, between $\mathrm{E55}$ and birth, axons lose their side branches and the eye-specific layers appear. By birth, nearly all axons have a smooth trunk and an elaborate terminal arbor restricted to the LGN layer appropriate to the eye of axon origin. When the number of side branches per axon was quantified, the time course of appearance and subsequent loss of side branches was found to parallel the time course of the initial intermixing of inputs and subsequent reduction in territory shared by the two eyes as determined from previous intraocular injection experiments. Our results also showed that the side branches along each axon were located primarily within LGN territory destined to be occupied by the other eye. Thus, the side branches are likely to represent a morphological substrate for the intermixing of inputs from the two eyes.

These observations suggest that the segregation of eye input to the LGN involves two fundamental and simultaneous events. One event is the remodeling of the branching pattern along the length of the main axon trunk so that the side branches present early on are eliminated and the main axon trunk becomes smooth.

\footnotetext{
Received May 1, 1985; revised July 23, 1985; accepted July 26, 1985.

We wish to thank Drs. Eric Knudsen, Murray Sherman, and Jack McMahan for their useful comments on the manuscript, Jerold Chun, Marla Luskin, Sandra Shotwell and Mark Siegel for their assistance with surgery, and Mark Nakamura for help in measuring axons. Thanks also to Mark Siegel for photographic assistance and Cecele Thomas for help with word processing. This research was supported by NIH Grant EY 02858, NSF Grant BNS 8317228, the March of Dimes, and the McKnight Foundation.

Correspondence should be sent to David Sretavan, Ph.D., and Carla J. Shatz, Ph.D., at the above address.

Copyright (C) 1986 Society for Neuroscience 0270-6474/86/010234-18\$02.00/0
}

The other is the addition of new axon to form a restricted terminal arbor located within the LGN layer appropriate to the eye of axon origin. Measurements of the total linear length of axon arbor with age show that the growth of terminal arbor far exceeds the retraction of side branches, demonstrating that a net growth of retinogeniculate axon arbor accompanies the formation of the eye-specific layers. Thus, selective retraction of side branches, coupled with continuous growth of the terminal arborization, contributes simultaneously to the reduction in the amount of territory shared by the two eyes and to the formation of the eye-specific layers.

The adult mammalian visual system is characterized by a high degree of order in the connections between the retina and the dorsal lateral geniculate nucleus (LGN). The most prominent feature of this retinogeniculate projection is the segregation of input from the two eyes into separate and alternating layers each made up of the axon terminals from the retinal ganglion cells of one eye only. For example in the cat, the contralateral eye projects to layer $\mathrm{A}$, the ipsilateral eye projects to layer $\mathrm{A} 1$, while the $\mathrm{C}$-complex consists of several thin leaflets that receive alternate inputs from the two eyes (Guillery, 1970; see also Fig. $1 B$ ). In addition to this arrangement into eye-specific layers, axons from neighboring ganglion cells in the retina terminate in adjacent sites within a layer, thereby forming a continuous and orderly retinotopic map.

To date, much of our information on the development of this projection has come from experiments using intraocular injections of tracers to label and examine the global retinal projection at a series of developmental ages. From studies of this type in monkeys (Rakic, 1977), opossums (Calvacante and Rocha-Miranda, 1978; Sanderson et al., 1982), hamsters (Frost et al., 1979; So et al., 1978, 1984), rats (Bunt et al., 1983), ferrets (CardLinden et al., 1981), and cats (Shatz, 1983), it has bcen shown that the precise connections present in the adult retinogeniculate projection arise from an initially diffuse pattern of connectivity. In cats, there is a period early in prenatal development when the inputs from the two eyes are intermixed and share common territories within the LGN. With time, the shared territory decreases as afferents from both eyes sort out from each other into the adultlike pattern of distinct eye-specific layers.

While the method of intraocular injection has been invaluable in defining the basic sequence of events leading to the formation of separate eye-specific layers, it cannot provide much information on the developmental events occuring at the level of individual retinal ganglion cell axons, which are, after all, the fundamental units of connectivity in this system. In the adult cat, reconstruction of single retinogeniculate axons intracellularly filled with HRP show that these axons have characteristic branching patterns in which all processes are restricted to a dense terminal arbor (Bowling, 1984; Bowling and Michael, 1980; Sur 
and Sherman, 1982). These terminal arbors, in turn, are located only in certain regions of the nucleus, corresponding to the layers appropriate for their eye of origin; the main axon trunk, as it courses through layers belonging to the other eye, is smooth and does not elaborate processes. This characteristic restricted branching pattern forms the underlying basis for the segregation of input from the two eyes. In addition, since individual terminal arbors are narrow and only occupy a small fraction of the mediolateral extent of a layer, the branching pattern of ganglion cell axons also contributes to the formation of the fine-grain retinotopic map present in each layer (Sanderson, 1971). Consequently, in order to learn how the pattern of eye-specific layers is cstablished during development from an initially intermixed state, it is essential to examine the morphology of individual ganglion cell axons from the time they first grow into the LGN until adultlike terminal arbors are formed.

Since the entire process of segregation occurs prenatally, we have developed an in vitro method to examine the branching pattern of single retinal axons filled with HRP during the development of this system. Among the questions addressed are, first, what do individual retinogeniculate axons look like during the initial period when inputs from the two eyes are known to be intermixed from the intraocular injection experiments? Second, what changes occur in the branching pattern of individual axons that could lead to a reduction in the intermixing of inputs and the emergence of layers? And third, since the development of the retinogeniculate projection also involves the formation of restricted and narrow terminal arbors, when and how does this feature of terminal arborization appear?

Our results show that throughout the development of this system, individual retinogeniculate axons grow extensively, and the formation of segregated layers from the intermixed pattern does not result from the large-scale retraction of axon arbors. Instead, the formation of eye-specific layers in the retinogeniculate projection appears, at least in part, to be due to a dynamic process in which the loss of small axon branches from areas of intermixing occurs simultaneously with the continuous elaboration of a restricted terminal arbor in the appropriate layer. A brief report of some of these results has been published (Sretavan and Shatz, 1984).

\section{Materials and Methods}

To examine the retinogeniculate system during the cat's prenatal development, we have devised a method in which fetal mammalian optic tract axons can be labeled with HRP in vitro. In the present study, a total of 21 fetuses aged between embryonic day 37 (E37) and birth (E65), and one postnatal (P2) kitten were used. Fetuses were delivered by cesarian section from timed pregnant cats bred for 24 to $48 \mathrm{hr}$. In $48 \mathrm{hr}$ breedings, the second day of breeding was counted as the first day of gestation, embryonic day 1 (E1). Table 1 summarizes the experiments included in this study.

\section{Surgery}

Cesarian sections were performed as described by Shatz (1983) with animals under general anesthesia using a mixture of halothane, nitrous oxide, and oxygen. Expired $\mathrm{CO}_{2}$ was monitored and maintained at 3.5$4.0 \%$. Ringer's solution with $5 \%$ dextrose was given intravenously in surgeries requiring intraocular injections of anatomical tracers. In addition, terbutaline sulfate (Geigy), in doses of $0.1-0.2 \mathrm{mg}$, was given when necessary to control uterine contractions.

\section{In vitro preparation}

After delivery by cesarian section, each fetus was perfused intracardially for 1-2 min with a mammalian Ringer's solution ( $285 \mathrm{mOsm}$ ) containing $5 \%$ glucose, oxygenated with $95 \% \mathrm{O}_{2}$ and $5 \% \mathrm{CO}_{2}$ at $32-34^{\circ} \mathrm{C}$ (for composition of Ringer's solution, see Shatz and Kirkwood, 1984). The heart continues rythmic contractions throughout this perfusion procedure. In fetuses aged E57 and older, phenobarbital sodium (Nembutal) was added to the oxygenated Ringer's solution $(5 \mathrm{mg} / 100 \mathrm{ml})$.
Table 1. Summary of age of each preparation, procedures performed, and number of axons reconstructed at each age

\begin{tabular}{|c|c|c|c|}
\hline Age & $\begin{array}{l}{ }^{3} \mathrm{H}-\text { Leu } \\
\text { intraocular } \\
\text { injection }\end{array}$ & $\begin{array}{l}\text { HRP filling } \\
\text { of axons }\end{array}$ & $\begin{array}{l}\text { Number of } \\
\text { axons recon- } \\
\text { structed }\end{array}$ \\
\hline \multicolumn{4}{|l|}{ Fetuses } \\
\hline E38 & + & + & 6 \\
\hline $\mathrm{E} 40$ & & + & 1 \\
\hline E41 & + & + & 2 \\
\hline E42 & & + & 7 \\
\hline E43 & + & + & 13 \\
\hline E43 & + & + & 8 \\
\hline E43 & + & + & 15 \\
\hline $\mathrm{E} 47$ & & + & 7 \\
\hline E48 & + & + & 14 \\
\hline E50 & & + & 9 \\
\hline E52 & & + & 9 \\
\hline E53 & + & + & 18 \\
\hline E53 & & + & 12 \\
\hline E54 & & + & 3 \\
\hline E54 & & + & 2 \\
\hline E57 & + & + & 8 \\
\hline E57 & & + & 1 \\
\hline E58 & + & + & 21 \\
\hline E63 & & + & 10 \\
\hline E63 & + & + & 2 \\
\hline E64 & + & + & 1 \\
\hline \multicolumn{4}{|l|}{ Newborns } \\
\hline $\mathbf{P} 2$ & + & + & 3 \\
\hline Total 22 & 12 & 22 & 172 \\
\hline
\end{tabular}

This initial perfusion facilitated the subsequent histological examination of HRP-filled axons by removing red blood cells.

After perfusion, fetuses were placed on ice and the cranium opened to expose completely the cortical surface. Cortical tissue overlying the LGN was carefully dissected away, and the diencephalon and midbrain were removed together and placed in $4^{\circ} \mathrm{C}$ oxygenated Ringer's solution. Each diencephalon preparation was then bisected along the midline and the resulting two halves pinned medial side down in a Petri dish.

\section{HRP labeling}

A concentrated solution of HRP in distilled water was allowed to dry almost completely and then used to coat the tips of glass micropipettes. With practice, HRP deposits of a variety of sizes can be coated onto pipette tips. With the aid of an operating microscope and a fiber-optic lighting system, deposits of HRP were made in the optic tract using the micropipettes held by a micromanipulator or by hand. Pipettes were left for 15-45 sec after placement into the tract. The sites of injection were located in the optic tract just ventral to the LGN and anterior to the medial geniculate nucleus. The schematic appearance of the preparation and the location of injection sites are shown in Figure $1 A$. The total elapsed time from the delivery of the fetus to the completion of the injection was approximately 5-7 min.

After HRP injection, the fetal preparations were immediately placed into a modified tissue slice chamber (see Shatz and Kirkwood, 1984, for more details) and continuously superfused with $32-34^{\circ} \mathrm{C}$ oxygenated Ringer's solution at a rate of $60-80 \mathrm{ml} / \mathrm{hr}$ for $4-6 \mathrm{hr}$ to allow for transport of label to the LGN.

\section{Histology}

At the conclusion of the in vitro incubation period, the fetal preparations were immersion-fixed in $1 \%$ paraformaldehyde, $1.25 \%$ glutaraldehyde in $0.1 \mathrm{M}$ phosphate buffer, $\mathrm{pH} 7.4$, at $4^{\circ} \mathrm{C}$. After overnight fixation (15$18 \mathrm{hr}$ ), the tissue was sectioned in the horizontal plane at $100 \mu \mathrm{m}$ on a 


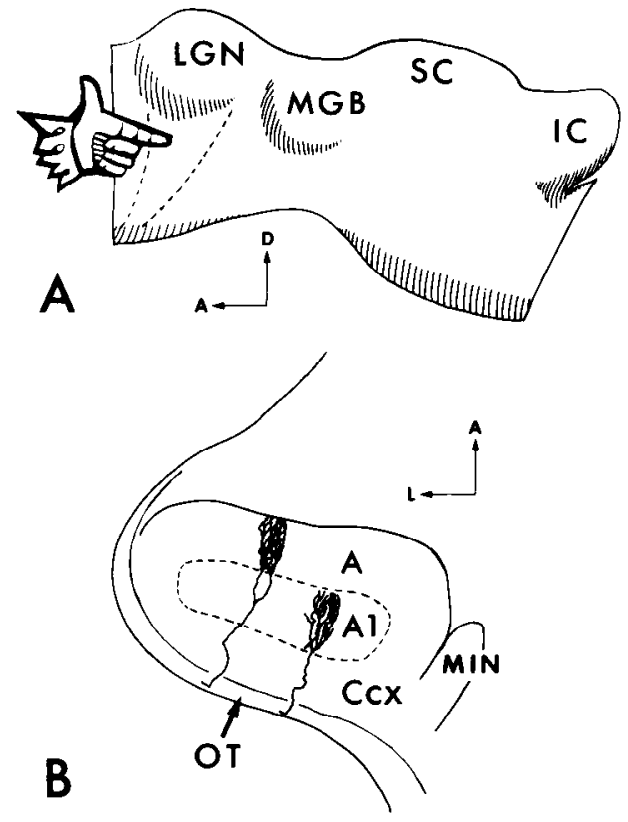

Figure 1. Schematic diagrams showing the in vitro preparation and the relationship between retinogeniculate axons, the optic tract, and layers of the LGN. $A$, Schematic representation of the lateral surface of an in vitro diencephalon preparation. The course of the optic tract as it runs along the lateral surface of the diencephalon dorsally up to the LGN is marked with dotted lines. HRP deposits were made into the optic tract just anterior to the medial geniculate body $(M G B)$, as indicated. $S C$, superior colliculus; $I C$, inferior colliculus. $B$, Diagram of a horizontal section through the LGN of a cat fetus approximately a week before birth. Two retinogeniculate axons are shown coursing into the dorsal LGN in a direction orthogonal to the optic tract; each gives off a restricted terminal arbor. The dotted lines in the dorsal LGN subdivide the nucleus into approximate thirds. The innermost third (furthest from the optic tract) corresponds to layer $A$, which receives input only from the contralateral eye in the adult. The middle third corresponds to layer $A 1$, an ipsilateral-eye layer. The outer third consists of the C-complex $(C c x)$, which is actually a series of several thin leaflets that receive alternate inputs from the two eyes. $O T$, optic tract; $M I N$, medial interlaminar nucleus.

Vibratome. The free-floating sections were reacted for HRP histochemistry using diaminobenzidine as the chromogen with $\mathrm{CoCl}_{2}$ intensification in $0.05 \mathrm{M}$ Tris buffer ( $\mathrm{pH} 7.2$ ) in a procedure modified from Adams (1981). Each section was then mounted on a glass slide in such a way that when the slides were stacked, the sections were in register with each other, thereby aiding in subsequent reconstruction of axons located in multiple sections.

From a previous study of retinogeniculate development using intraocular injections of tracers (Shatz, 1983), it was found that the entire process of segregation in the LGN during fetal development is best visualized in the horizontal plane. It is only after the adultlike pattern of eye-specific layers has emerged by birth that the LGN undergoes the $90^{\circ}$ rotation in the sagittal plane that brings it to its adult orientation (Kalil, 1978). From results obtained here, it was very clear that the horizontal plane of section is indeed the most appropriate for analysis throughout prenatal development, since the retinal axons and their arbors were aligned in this plane and required a minimum number of sections for reconstruction.

\section{Analysis}

HRP-filled axons were examined using a $63 \times$ planapo objective (Zeiss, oil, NA 1.4) at a total magnification of $790 \times$ and reconstructed using a camera lucida with the tracings at a final total magnification of $1030 \times$. A blue filter was used to enhance contrast between HRP-filled axons and background. Although the LGN undergoes a certain amount of displacement and rotation in the medial to lateral direction during prenatal development due to the growth of more medial structures, the relationship of the LGN to the optic tract remains constant (Shatz,
1983). Retinal ganglion cell axons run from the chiasm dorsally within the optic tract, then make a right-angle turn to enter the LGN. Within the LGN, the trajectories of axons from both the contralateral and the ipsilateral eye run perpendicular to the plane of the future layers, and after segregation is complete, axons arborize only within their respective layers. A schematic diagram showing the relationship of the optic tract, the layers of the LGN and the trajectory of the retinal afferents in a horizontal section at about a week before birth are shown in Figure $1 B$.

Reconstructed axons fulfilled the following criteria: (1) Axons were unambiguously located within the LGN. (2) Axons were completely and continuously filled, i.e., no gradual fading was seen in distal processes, and continuous labeling was present at branch points. (3) Axons could be traced easily and were not confused with other filled axons nearby. (In practice, HRP-filled axons located in areas without any other HRPpositive profiles can be easily found.) (4) Axons showed no signs of degeneration. (Only very infrequently were beaded axons seen.) (5) The entire terminal arborization of axons could be reconstructed from serial sections and traced all the way back into the region of the optic tract.

Axons were reconstructed from up to eight sections. The majority required only three to four sections, demonstrating the suitability of sectioning in the horizonal plane. A total of 172 axons from layers $A$ and $A 1$ fulfilling the above criteria were reconstructed in this study (see Table 1 for more details).

\section{Combination of in vitro HRP axon fills with intraocular injections of ${ }^{3} \mathrm{H}$-leucine}

One of the major aims of this study was to identify the morphological basis for the intermixing of the projections from the two eyes at the level of individual axons. We wished to examine the possibility that intermixing is due to individual axons with processes that initially extend into territory destined to be occupied by the other eye. To investigate this possibility, intraocular injections of tritiated leucine were used to identify the locations of the future layers during the time when the two sets of afferents were well on their way to being completely segregated from each other. In the same animals, retinogeniculate axons were then filled with HRP and reconstructed. By doing this, the pattern of arborization of HRP-labeled axons could be correlated directly with the location of the future layers as revealed autoradiographically, permitting an answer to the question of whether axons from one eye give off processes in territory belonging to the other eye.

In this series of experiments, an intraocular injection of $250-500 \mu \mathrm{Ci}$ of ${ }^{3} \mathrm{H}$-leucine (NET-135H: specific activity $40-60 \mathrm{Ci} / \mathrm{mmol}$ ) in $10-25$ $\mu \mathrm{l}$ of $0.9 \%$ saline was made into one eye of each fetus to be studied (as described in Shatz, 1983). After waiting $24 \mathrm{hr}$ to allow for the transport of the radioactive label to the LGN, the animal was delivered by cesarian section and retinogeniculate afferents were labeled with HRP using the in vitro method. Following completion of analysis and reconstruction of HRP-labeled axons, the slides containing the relevant tissue sections were de-coverslipped by immersion in xylene for $48 \mathrm{hr}$ and then quickly rehydrated. A single sheet of tritium-sensitive LKB-Ultrofilm (LKBprodukter AB, Sweden) was applied directly onto the sections and placed into light-tight $x$-ray film cassettes for $10 \mathrm{~d}$. The LKB film was then developed using D- $19\left(5 \mathrm{~min}, 20^{\circ} \mathrm{C}\right)$ and Rapid Fix $\left(5 \mathrm{~min}, 20^{\circ} \mathrm{C}\right)$. LKB film was used to visualize the pattern of projection from the injected eye instead of conventional liquid emulsion autoradiography, which would have prevented the reexamination of individual labeled axons within the section. However, a few sections were processed using conventional autoradiographic techniques to demonstrate the faithful replication of the labeling pattern by LKB film. These sections were coated with NTB-2 emulsion, as described by Shatz (1983). We found very good correlation between the labeling patterns using liquid emulsion autoradiography and LKB film.

\section{Results}

The in vitro method of labeling retinal afferents with HRP in the fetal visual system works well. Growth cones from the youngest fetal ages, as well as complete retinogeniculate arbors found in perinatal animals, can easily be visualized. Examples of each are shown in Figure 2 . Figure $2 A$ shows a portion of the optic tract adjacent to the LGN containing several HRP-filled profiles that wc belicve to be growth concs. These structures are relatively simple, with a single bulbous ending and a leading filopodium; they resemble growth cones of retinal ganglion cells 

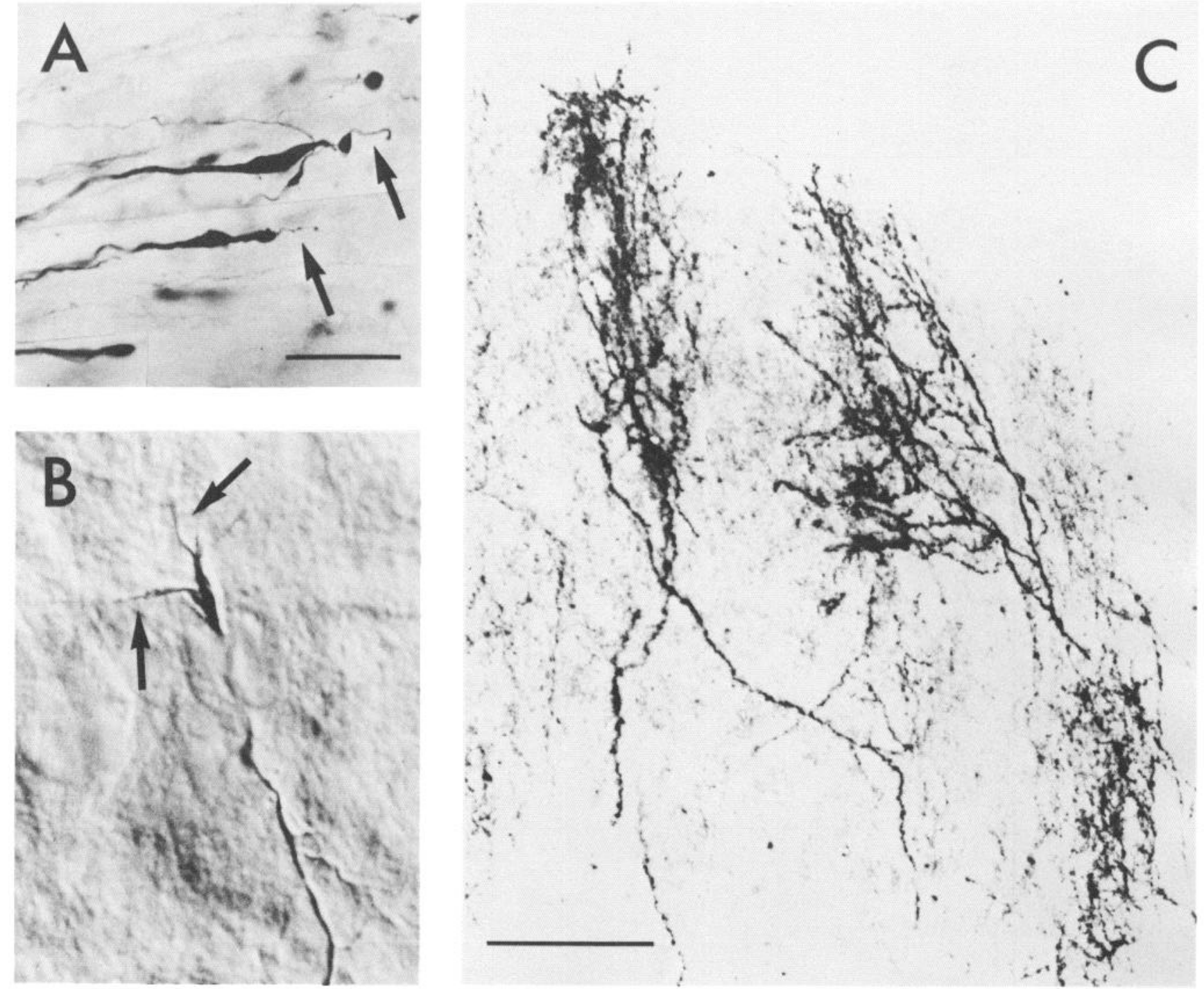

Figure 2. Photographs of growth cones and retinogeniculate terminal arbors filled with the in vitro method. A, HRP-filled growth cones in the optic tract of an E57 fetus. These structures are simple, with a bulbous ending and single filopodium (arrow). Scale bar, $5 \mu \mathrm{m}$. B, An HRP-filled growth cone in the LGN of an E53 fetus. Growth cones encountered in the nucleus often have several filopodia extending in different directions (arrows). Scale bar, same as in B. C, Bright-field photograph showing the terminal arbors of two retinogeniculate axons within layer A of the LGN in an E63 fetus. The in vitro method results in good filling of relatively complex terminal arbors in the fetal LGN, similar in size and shape to those seen in postnatal kittens (Sur and Sherman, 1982). Scale bar, $100 \mu \mathrm{m}$.

seen within the LGN of neonatal cats (Mason, 1982). In this study, growth cones were still seen within the optic tract in surprisingly old fetuses: The growth cones illustrated in Figure $2 A$ were at E57 just 1 week before birth and a full $25 \mathrm{~d}$ after the last retinal ganglion cells are generated (Kliot and Shatz, 1982; Walsh et al., 1983). Growth cones were also often seen within the LGN. Figure $2 B$ shows a growth cone from an E54 fetus in Nomarski optics. It is our impression that growth cones seen within the LGN often have more filopodia (see arrows) than those in the tract, although we have not attempted a thorough analysis of this observation.

Elaborate terminal arborizations of individual retinogeniculate axons were also routinely filled. Two retinogeniculate arbors from an E63 fetus, $2 \mathrm{~d}$ before birth, are shown using bright-field optics in Figure $2 C$. In this figure, the main axon trunks are not included. The optic tract (not shown) is located toward the bottom of the figure. The two HRP-filled arbors terminate in layer $\mathrm{A}$ and are therefore afferents from the contralateral eye. The overall shape and morphology of these arbors are remark- ably similar to those filled by intracellular injections of HRP in 3- to 4-week-old kittens (Sur et al., 1984). The routine filling of growth cones, including filopodia as fine as $0.1 \mu \mathrm{m}$ in diameter, and extensive retinogeniculate terminal arbors, as shown here, suggest that this in vitro method can be used to fill fetal mammalian axons reliably and completely. Nevertheless, there is always the possibility that the finest processes or filopodia fail to fill completely or that the method itself somehow perturbs the fine-detailed morphology of axons and growth cones.

\section{Axon bifurcations in the optic tract}

It is known in the adult cat that over $90 \%$ of the $\beta$ - or X-type retinal ganglion cells project exclusively to the dorsal LGN (Illing and Wässle, 1981), while almost all the $\alpha$ - or Y-type cells that project to the LGN also send a collateral to the medial interlaminar nucleus (MIN) and the superior colliculus (SC) (Bowling, 1984; Bowling and Michael, 1980; see Wässle, 1982, for review). In the fetal preparations, axons that arborized exclusively within the LGN A-layers without sending a collateral 

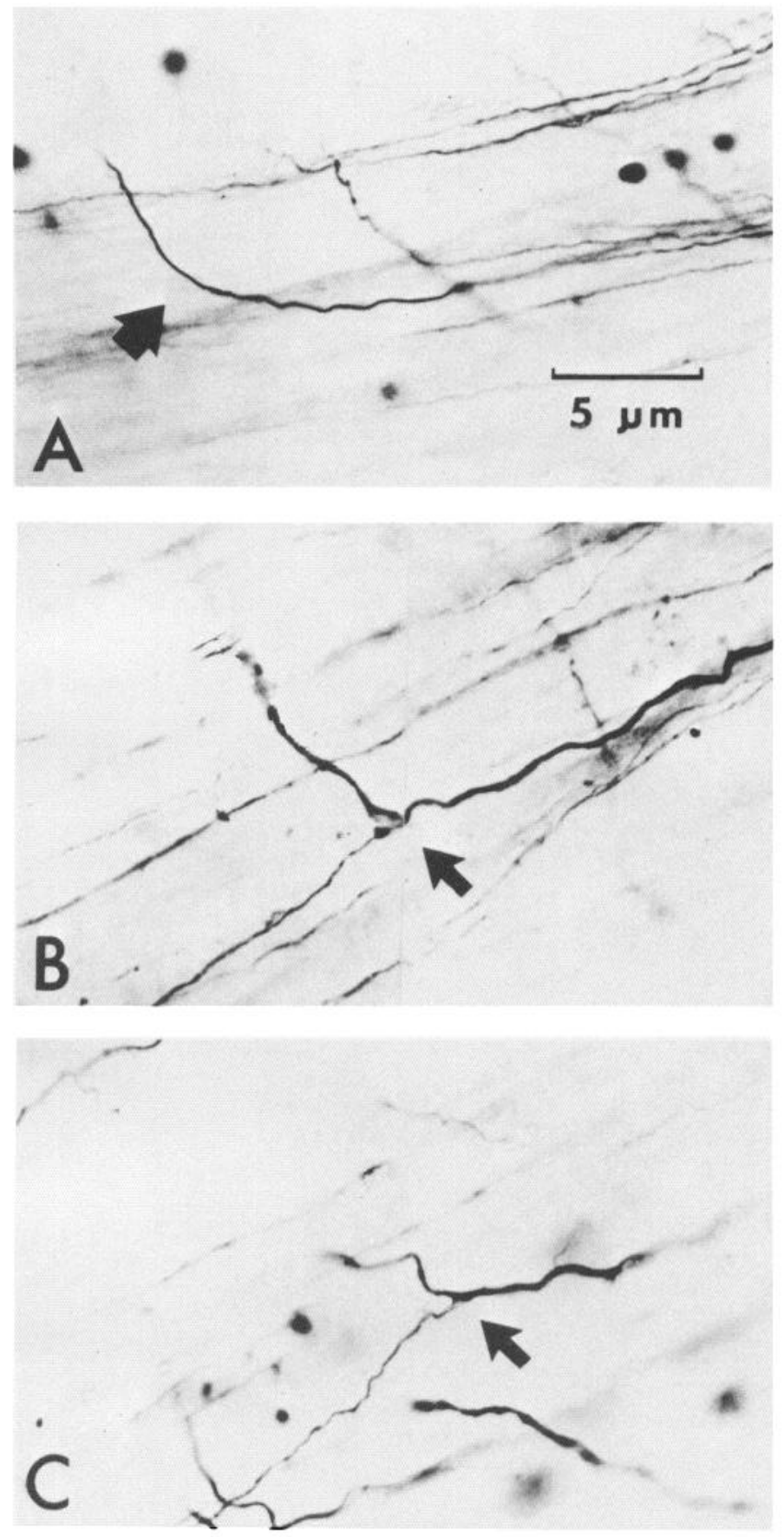

Figure 3. Examples of HRP-filled fetal retinal axons coursing in the optic tract. $A$, An example of a retinal axon that turns at right angle to enter the LGN (arrow) without sending a collateral to more posterior structures. $B$ and $C$, Examples of retinal axons within the optic tract that, in addition to sending a branch to the LGN, also bifurcate in the optic tract (arrows) and send collaterals to more posterior structures. Scale bar, $5 \mu \mathrm{m}$ for all three panels.

to more posterior structures were commonly seen. However, some axons with extensive collateral projections to LGN and MIN and with a process continuing on in a posterior direction were also found in our material. Examples of both types of axons, as they leave the optic tract to innervate the LGN, are shown in Figure 3. In all three panels, axons are shown within the optic tract along the lateral border of the LGN running from left to right. The LGN (not shown) is toward the top in each panel, while more posterior structures such as the MIN and SC are toward the left. In Figure $3 A$, an axon is shown leaving the optic tract to turn into the LGN. This axon does not bifurcate within the optic tract. In Figure $3, B$ and $C$, each axon bifurcates to send one branch into the LGN while the other continues in a posterior direction. In Figure 4, two retinogeniculate axons have been completely reconstructed from multiple sections. In Figure $4 A$, an axon from an E53 fetus is shown turning abruptly to leave the optic tract and run into the LGN. This retinogeniculate afferent projected only to the LGN. After leaving the optic tract, it traversed across the LGN straight toward the inner border and then elaborated a terminal arborization within layer A. In Figure $4 B$, an axon from an E57 fetus gives off an elaborate arborization within layer $A 1$ of the LGN and a single extension into layer A. In addition, a collateral projection is sent to MIN. From MIN, the parent axon continues to travel in a posterior direction toward the SC. These observations suggest that our methods fill several classes of retinal ganglion cell axon. However, the possibility that retinal ganglion cells during fetal development elaborate collaterals to several CNS visual targets, some of which are eliminated while others are maintained, cannot be excluded. It is worth emphasizing here that the results and conclusions presented below are valid regardless of this issue, because we are principally interested in the formation of eye-specific layers within the LGN.

\section{Sequential changes in axon branching pattern during the formation of eye-specific layers}

From a previous study in which the development of segregated layers of eye input was examined by intraocular injections of tracers to visualize the global pattern of retinal input in the cat, it is known that retinal axons invade the LGN by around E32, close to the halfway point in the cat's gestational period of 65 d (Shatz, 1983). Axons from the contralateral eye innervate the LGN several days ahead of those from the ipsilateral eye. As a likely consequence of this difference in time of arrival, the innermost one-third of the LGN (e.g., the territory furthest from the optic tract-see Fig. $1 B$ ) is occupied by contralateral afferents throughout development and eventually becomes the contralaterally innervated adult layer A. Between E32 and E48, axons from the two eyes grow into the LGN and are intermixed within a substantial portion of the nucleus. By E48, the amount of LGN territory shared by the two eyes is close to maximum, but even so, the contralateral eye occupies almost exclusively the innermost rim of future layer A (see Shatz, 1983, Fig. 13). Then, during the next $10 \mathrm{~d}$ (E48-58), the projections from the two eyes sort out, and, in doing so, regions exclusively occupied by one or the other eye appear as the amount of intermixing decreases between the two sets of afferents. For example, the contralateral projection slowly retreats from the middle portions of the nucleus, leaving this territory occupied exclusively by ipsilateral afferents (this territory corresponds to adult layer A1). A similar process is repeated in the remainder of the nucleus, as both contralateral and ipsilateral projections disappear from selected territories. The nonoverlapping alternating regions of eye input corresponding to layers $\mathrm{A}$ and $\mathrm{A} 1$ become evident by E60. By birth ( $5 \mathrm{~d}$ later), the pattern of afferent input to the whole nucleus has taken on an adultlike appearance. Accordingly, in this study we have concentrated our efforts on the period between E38 and P2, the time over which this process of intermixing and segregation occurs.

A representative selection of retinogeniculate axons between E38 and P2 taken from our collection of 172 reconstructed axons is shown in Figures 5-7. Every axon selected for illustration arborized entirely within the confines of the dorsal LGN and the samples at each age presumably include axons from both eyes. However, here no attempt has been made to identify conclusively the ocular affiliation of each axon. Identification requires the combined HRP- ${ }^{3} \mathrm{H}$-leucine approach (see Materials 


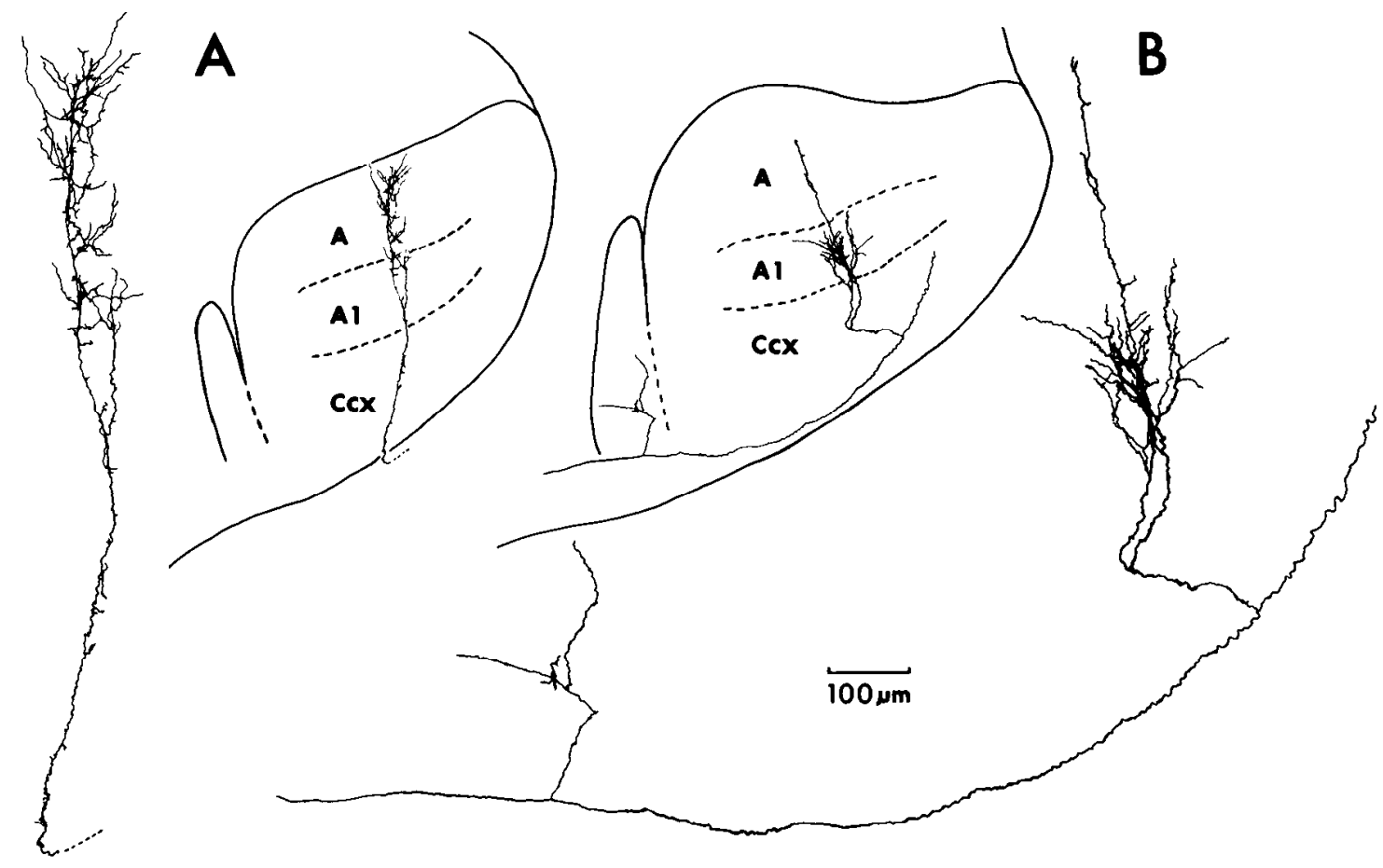

Figure 4. Diagram showing the complete reconstructions of two retinogeniculate axons in the LGN. In each case, the location of the axon and its terminal arbor with respect to the layers of the LGN is shown in the inset. Axon A from an E55 fetus runs into the LGN in a direction orthogonal to the optic tract and forms a terminal arbor in layer $A$. It does not have a collateral heading for more posterior structures. Axon B from an E57 fetus runs into the LGN, arborizes in layer $A 1$, and has a single long process into layer $A$. In addition, it also sends a collateral to the medial interlaminar nucleus (MIN) and continues on in a posterior direction toward the superior colliculus.

and Methods) and will be presented below in the discussion of morphological correlates of intermixing and segregation. In each figure, axons from several ages are presented together as a group in order to highlight morphological differences between the retinal afferents as they mature. In all three figures, axons have been reproduced at the same scale and are oriented with the optic tract toward the bottom of each figure and the inner border of the LGN toward the top. The axons have also been arranged with respect to the complexity of their morphology from left to right and top to bottom. In the following section, we have divided the description of the progressive morphological changes in retinogeniculate axons into three parts: before the onset of segregation of eye input, during segregation, and after the formation of eye-specific layers.

\section{Axon morphology before the onset of segregation}

E38-41 (Fig. 5). The axons seen in our youngest preparations were extremely simple. At these early ages, the LGN is only a thin sheet of cells located adjacent to the optic tract. Most of the axons shown here leave the tract and run across the entire extent of the nucleus with little or no branching. Growth cones can often be seen (at higher magnification) at the distal tips of the axon processes.

E42-43 (Fig. 5). The majority of axons seen at these ages are longer than those at E38-41 and have many delicate side branches that stud the main axon trunk along its course through the LGN. These side branches are short and do not project very far away from the main axon trunk. The territory of the LGN occupied by each axon, including side branches, is an approximately cylindrical column about $100 \mu \mathrm{m}$ or less in diameter. In any given experiment in this age group, we found a wide variation in axon morphology, from the simplest axons with only the bare essentials of an axon trunk, to axons that appear already to have a well-defined terminal arbor (for example, the last axon at the bottom right-hand corner of Fig. 5).

\section{Morphology during segregation}

E47-50 (Fig. 6). After a week of further development, nearly all axons possessed numerous side branches. As before, these were distributed along the entire length of the main axon trunk. The increase in side branches scen at this age correlates nicely with the fact that this is a period in which the projections from the two eyes share a large area of the LGN. Many axons now also show the outlines of a simple terminal arborization.

E53-55 (Fig. 6). Axons with many side branches are still evident at this age. The majority of axons are of two general types. One type exhibits an immature framework of terminal arborization that consists of several long processes grouped together at the distal end of the axon. On these axons, side branches are still present on portions of the main axon trunk away from the terminal arbor. A second more mature type of axon with elaborate and well-formed terminal arborizations is also seen (for example the two axons at the bottom right-hand corner of Fig. 6). Furthermore, from an examination of all the axons in this age group, it appears that the presence of the mature terminal arbor on these axons is correlated with a reduction in the number of side branches.

From previous work (Shatz, 1983), it is known that, by E5355 , the projections from the two eyes have begun to segregate from each other, and consequently it is possible to identify the locations of future layers A and Al. Our finding here that some axons already have well-formed terminal arbors at these ages is therefore perfectly consistent with the fact that segregation of eye input has progressed sufficiently so that layers can be delineated.

End of segregation and appearance of separate afferent layers E57-58 (Fig. 7). The majority of axons at these ages have a smooth main trunk ending in a restricted terminal arbor. The side branches characteristic of more immature axons at earlier 
240

Sretavan and Shat

E38-41

$E 42-43$
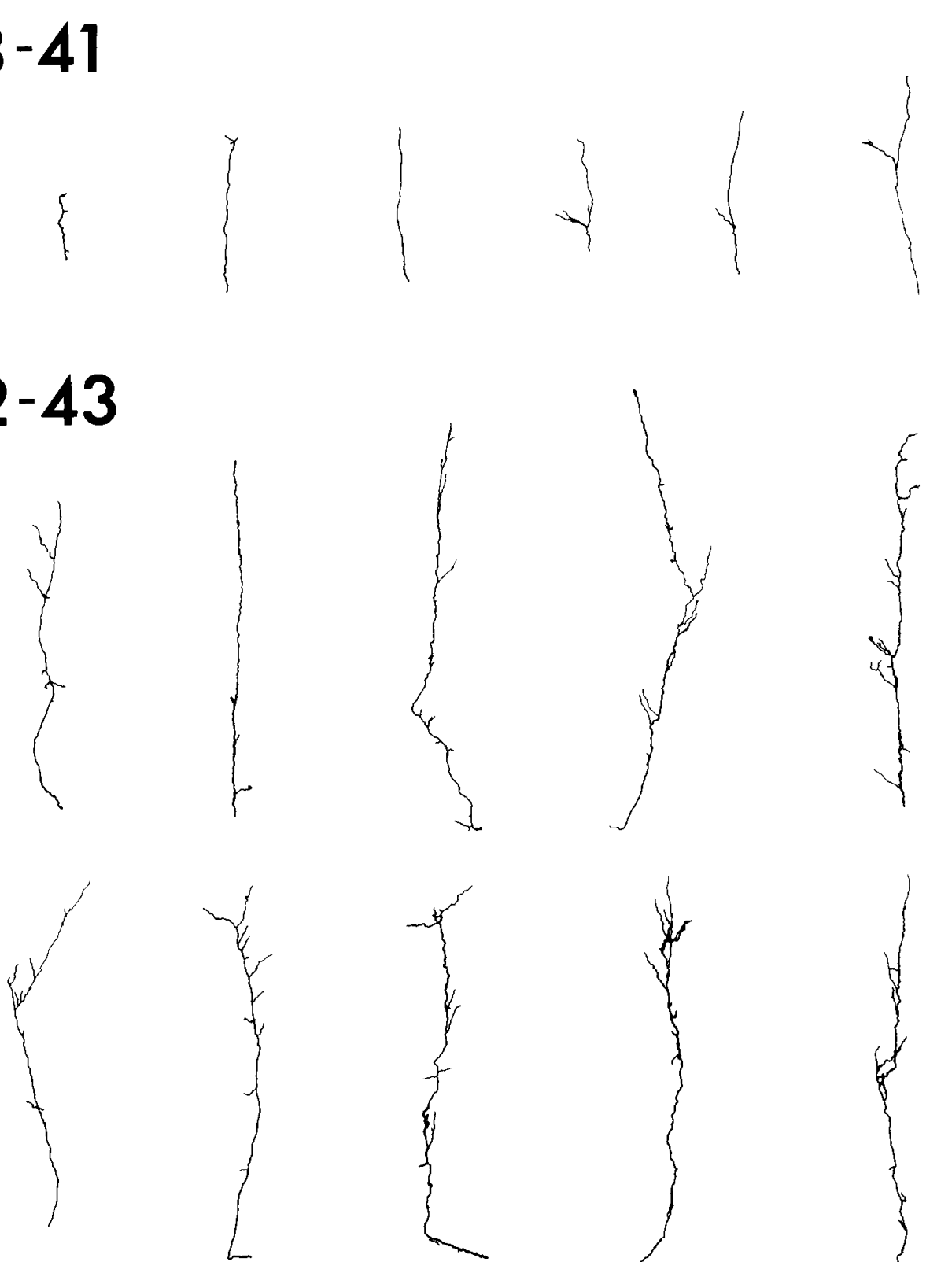

Vol. 6, No. 1, Jan. 1986
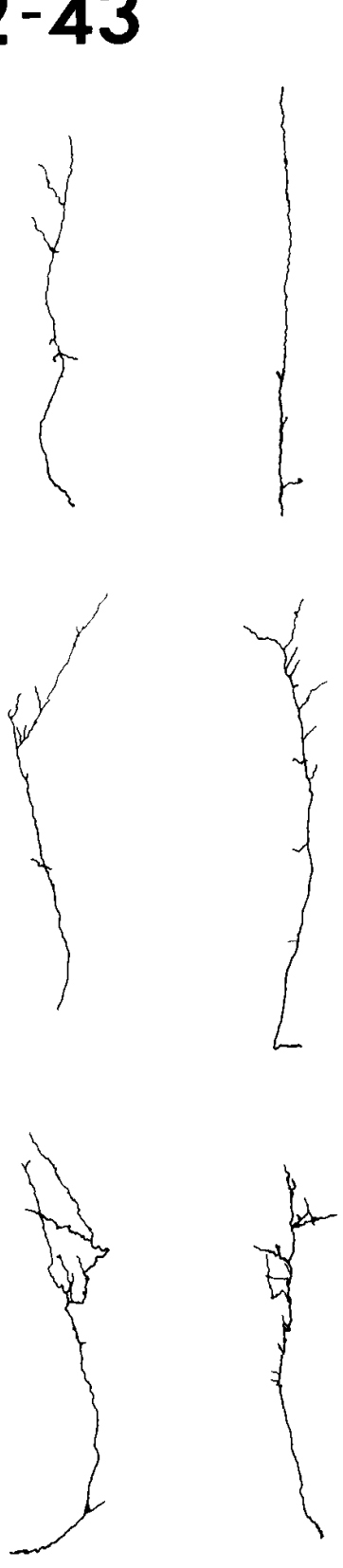
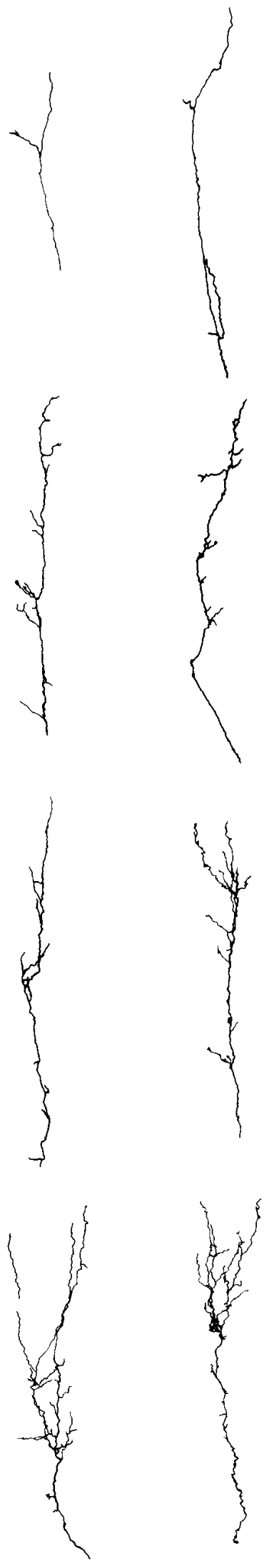

Figure 5. Reconstructions of retinogeniculate axons between E38 and E43. All axons are oriented with the optic tract (not shown) toward the bottom of the page and the innermost border of the LGN at the top. Most axons at these ages are simple and have a single main axon with side branches. Several axons with many more processes are shown at the bottom right of the figure. Scale bar, $100 \mu \mathrm{m}$. 
E 47-50
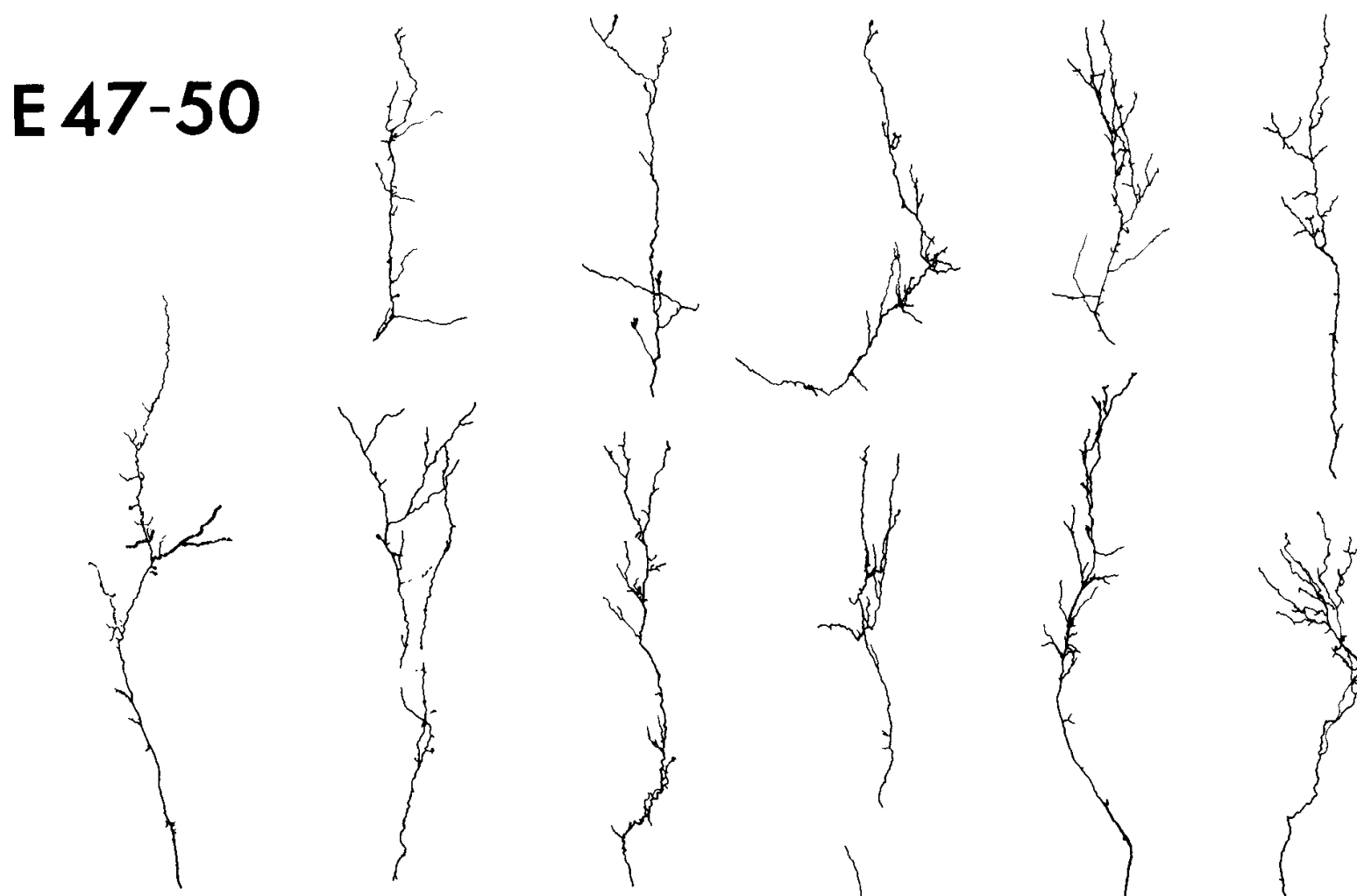

E 53-55
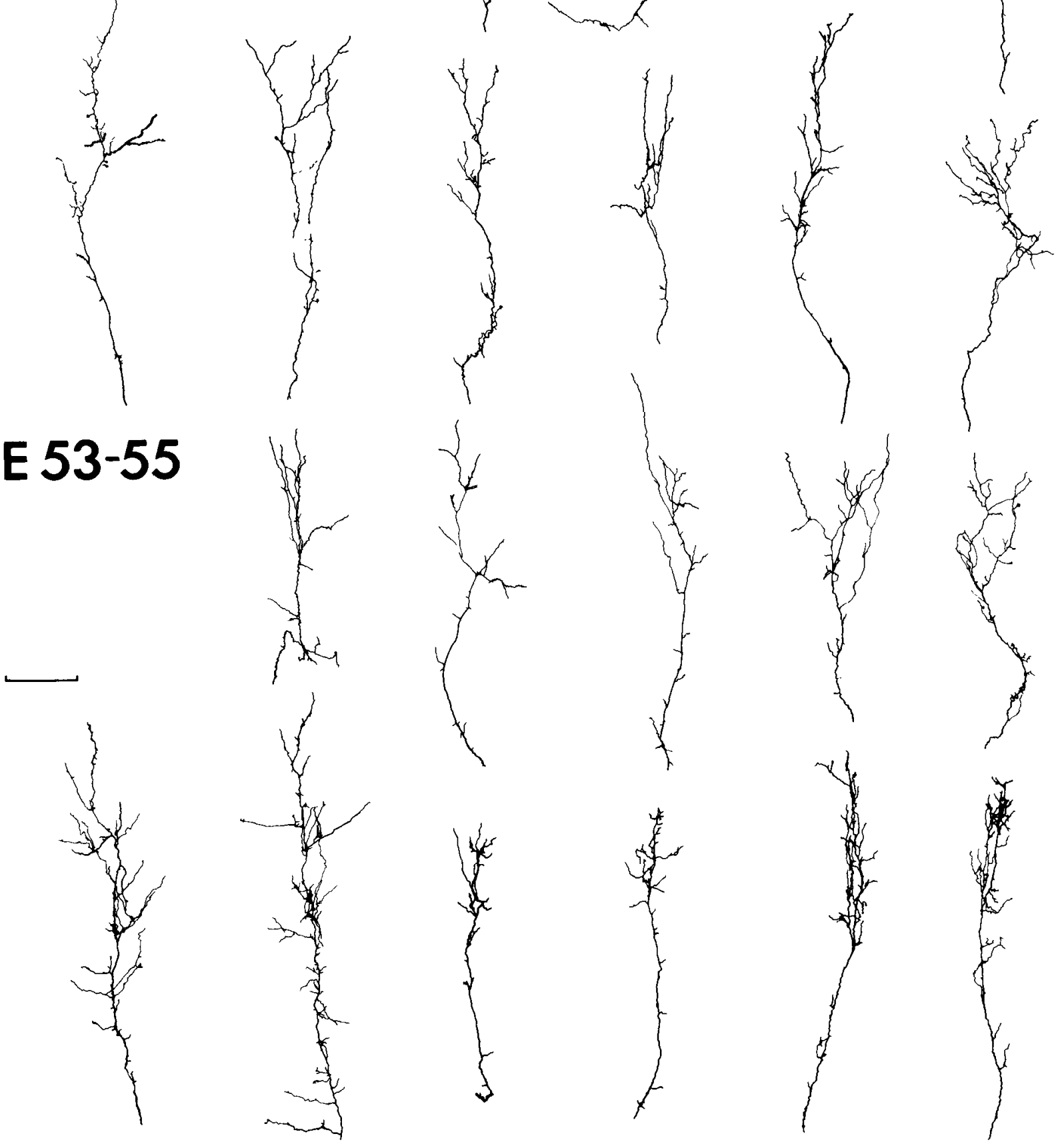

Figure 6. Reconstructions of retinogeniculate axons between E47 and E55. Axons are oriented as in Figure 5. During the period of intermixing of afferent input and the beginning of segregation, axons are studded with many side branches along the entire course of the main axon. The presence of a distal process that forms the framework of a terminal arbor on some axons (bottom right of figure) is associated with a decrease in the number of side branches. Scale bar, $100 \mu \mathrm{m}$. 


\section{E 57-58}
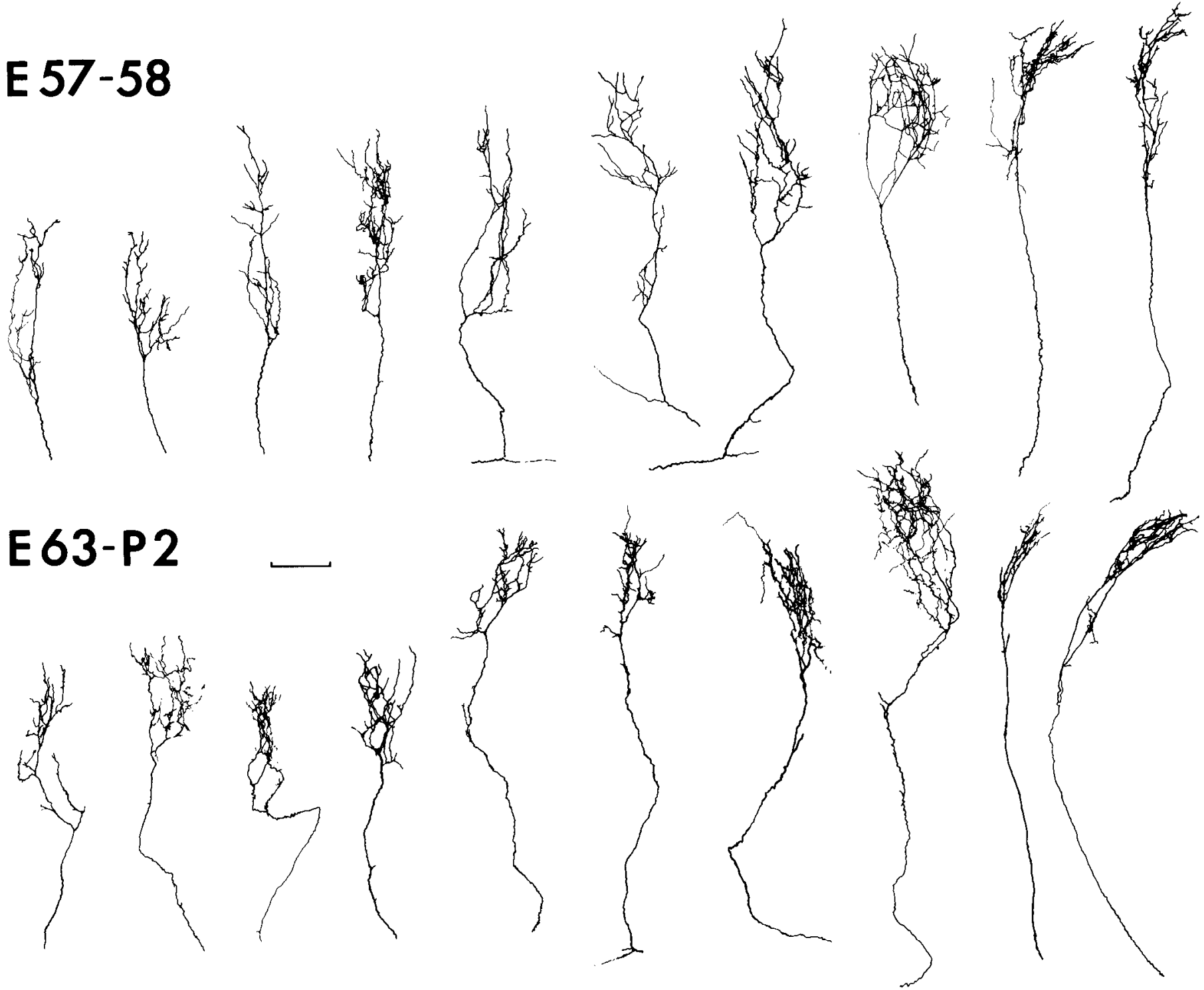

Figure 7. Reconstructions of retinogeniculate axons between E57 and P2. Retinal axons are oriented as in Figure 5. After the emergence of eyespecific layers, axons have correspondingly well-developed and dense terminal arbors but smooth axon trunks. Side branches are rarely found along the trunks of axons in older fetuses and neonates. Scale bar, $100 \mu \mathrm{m}$.

fetal ages are uncommon. The terminal arbors of these axons show some variation in their complexity. Some axons have only a simple framework of an arborization, while many have a relatively dense and complex arbor from which many fine terminal processes protrude.

E63-P2 (Fig. 7). Axons found at these ages are even more claboratc and look rather adultlike in their morphology. They have a dense plexus of terminal branching, while the main axon trunk is completely smooth and side branches are rarely found. Note that at these later ages (E57-P2), since the LGN layers are clearly defined on the basis of eye injection experiments, it is highly likely that the shorter axons shown in Figure 7 originate from the ipsilateral eye, while the longer axons are from the contralateral eye.

In order to summarize the progressive morphological changes in retinogeniculate axons throughout the period of prenatal development, we have separated the axons into four classes based on their appearance. The four classes are as follows:

1. Simple axons with a main axon trunk and one or two short branches.
2. Axons with side branches protruding from the main axon trunk, but without any evident terminal arbor.

3. Axons in which the framework of a terminal arbor is present but which also have some side branches along the main axon trunk.

4. Axons with a dense terminal arbor and a smooth trunk devoid of side branches.

By classifying axons from E38 to P2 according to the above criteria, the proportion belonging to each of these four classes at each fetal age was determined; the results are shown in histograms of Figure 8. In this figure, each histogram represents the percentage of reconstructed axons belonging to one of the four morphological classes during particular fetal periods or at P2. The results in Figure 8 show that, with increasing age, the shape of axons changes from a period when the majority (63\%) have only a simple main trunk (E38-42) to periods when side branches are commonly found along the main axon trunk. With further development, the axons acquire elaborate terminal arbors and lose their side branches (E57-P2). The results shown here also strongly imply that these four morphological classes 
actually represent a continuum of developmental change undergone by each retinal axon during prenatal life.

\section{Growth of retinogeniculate axon arbors}

From the results presented so far, it is apparent that by birth, retinogeniculate axons have a relatively complex terminal arbor that is restricted to a localized portion of the nucleus; no extraneous processes are given off the main axon trunk elsewhere within the LGN. This restricted pattern of arborization forms the basis for the adultlike pattern of eye-specific layers of afferent input that is present by these ages. The question naturally arises whether the development of this restricted pattern of terminal arborization is accompanied by arbor overgrowth followed by retraction or, instead, as seems likely from our direct observations above (Figs. 5-7), is a simple consequence of continued focused growth of the terminal arbor. To examine this question in more detail, we first measured the total length of all axon segments contributing to the terminal arborization of a number of axons at several fetal ages and plotted the results graphically in Figure 9. (Side branches, when present, were also included in the measurements.) The graph shows quite clearly that throughout the prenatal period during which afferents from the two eyes are first intermixed (E43-48) and then segregate (E4860 ) from each other, there is continuous and roughly linear growth in the terminal arbors of retinogeniculate axons.

If axon membrane is being added to the terminal arbors, as shown in Figure 9, then arbors could either become wider or denser. Either change would have implications for the development of a fine-grain retinotopic map within the LGN. From examining axons at different ages such as those presented in Figures 5-7, it appears that the terminal arbors of retinal axons are rather narrow throughout fetal development and do not run for long distances within the plane of a layer (parallel to the optic tract).

This impression was verified quantitatively by measuring the width of axon terminal arbors at various ages and plotting the results, as shown in Figure 10. The width of each arbor was measured at the point where the broadest arborization or side branches was found (parallel to the plane of the layers or optic tract). Figure 10 shows that there is an early phase of steady increase in width until about E48, when simple terminal arbors can first be recognized (cf. Fig. 5). Then arbor width remains remarkably constant at about $100 \mu \mathrm{m}$ for the remainder of prenatal development. Taken together with the results of Figure 9 , this implies that growth of the terminal arbor is such that the density of arborization increases within a fixed framework defined by the initial arbor set out at E48 or thereabouts.

\section{Morphological correlates of intermixing and segregation}

One of the major goals of this study was to identify, at the level of individual retinogeniculate axons, those morphological features responsible for producing the intermixed pattern of projection as revealed following intraocular injections of anterograde tracers. The peak period of intermixing occurs between about E44 and 54 (Shatz, 1983), and it was therefore intriguing to note that it is preciscly during, but not after, this period that the majority of axons reconstructed had many side branches distributed along their lengths (see Figs. 5-8). We wondered if the side branches could be a morphological correlate of the intermixing of afferent input from the two eyes seen following eye injections. If so, it seemed to us that at minimum two requirements should be satisfied: (1) The number of side branches per axon should increase and decrease with a time course similar to the known time course of intermixing and segregation of eye input within the LGN (Shatz, 1983), and (2) the location of side branches on axons from one eye should coincide with LGN regions destined to be occupied in the adult by afferents from the other eye. As we will show below, both these requirements can be fulfilled.
To investigate the first requirement, we counted the number of side branches on completely reconstructed axons at various ages (Fig. 11). Only side branches along the main axon trunk were counted (the terminal arbor was excluded). In young axons, where no recognizable terminal arbor is present, only side branches along the proximal two-thirds of the main axon shaft were counted, since processes in the distal third of the axon will likely contribute to the formation of the terminal arbor. In Figure 11 , the histogram for each age group represents the distribution in number of side branches found on the axons examined. The number of axons examined at each age group is shown at the top of each histogram.

As can be seen from Figure 11, between E38 and E55 there is a steady increase in the number of axons with side branches and also of side branches per axon. After E55, however, there is a rapid decrease until birth, when no side branches are found. Between E41 and E55, approximately $90 \%(83 / 95)$ of all axons examined had side branches. The remaining 12 axons (10\%) that did not have any side branches were of two types. Between E38 and E43, six axons did not have side branches, and all were very simple, with only a single main axon trunk. The other six axons were found between E47 and E55, and these were among the most mature looking in their arborization pattern. The presence of these two types of axons is expected in view of the observed variation in maturity of axons at any given fetal age (see Figs. 5-8). Thus, as required, the overwhelming majority of axons have side branches during the time when projections from the two eyes are intermixed. Subsequently, during the period between E56 and P2, when segregated layers of afferent input have emerged, the majority of axons are completely smooth along the entire course of their main axon trunk. In addition to the axons that were completely reconstructed and therefore included in Figure 11, a large number of axons were examined in detail at E63 and P2 for the presence of side branches; these were very rarely found. In sum, then, the presence of side branches on nearly all axons between E41 and E55 and their subsequent disappearance from axons at later postnatal ages correlates well temporally with the periods of intermixing and segregation leading to the development of eye-specific layers in this system.

Next, we will show that the side branches along a given axon are indeed located within territory that ultimately belongs to the other eye (e.g., requirement number 2 , above). To do this, the simplest approach would be to directly inject axons within the optic nerve with HRP rather than within the optic tract so that their identity with respect to eye of origin is known. Unfortunately, our attempts to do this did not produce satisfactory filling of axons in the LGN. Another approach makes use of the previous observation (Shatz, 1983) that the region of the nucleus furthest from the optic tract (e.g., the innermost rim of future layer A) is almost exclusively occupied by afferents from the contralateral eye throughout development. Consequently, any axon that traverses the entire nucleus and extends its arbor to the innermost border is very likely to originate from the contralateral eye. Furthermore, during the formation of eye-specific layers, the contralateral projection retreats from the middle third of the nucleus, leaving this territory occupied exclusively by afferents from the ipsilateral eye (future layer A1). Therefore, any axon that traverses the entire nucleus and also gives off side branches along its main axon trunk in the middle third of the LGN is highly likely to be a contralateral-eye axon with branches in territory belonging to the ipsilateral eye.

This situation is illustrated in Figure 12, a collection of eight axons at different ages between E38 and E63 likely to be from the contralateral eye because of their traverse across the LGN to its inner border. The relationship of four of these axons to the nuclear borders and optic tract is illustrated in the schematic diagrams below. As predicted, the axons at E48 and E53, during the period in which the projections from the two eyes are intermixed, have side branches not only in the middle third of 

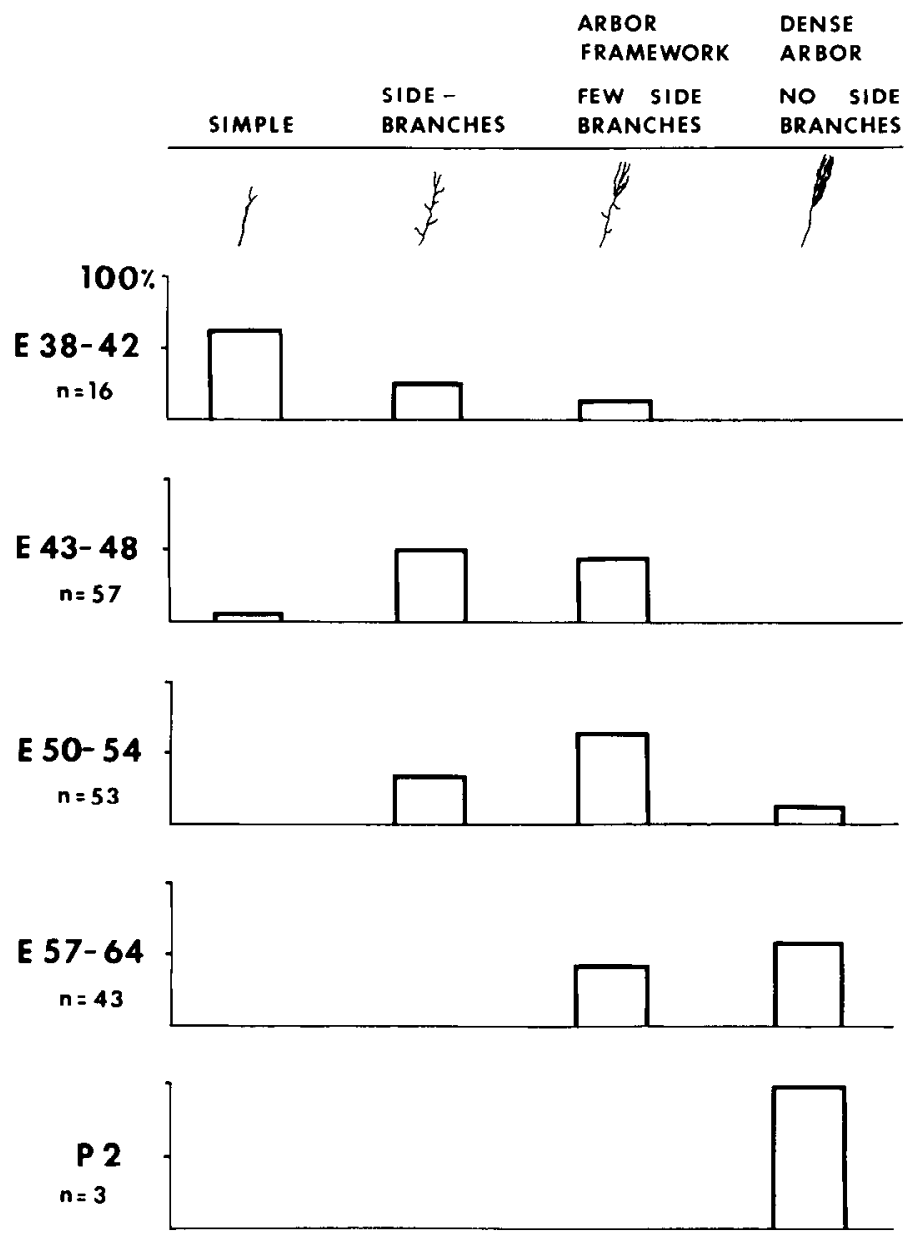

Figure 8. Histograms showing the proportions of reconstructed axons belonging to each of four morphological classes during different fetal periods and at P2. Representative appearance of each morphological class is shown at the top (see text for more detail). With increasing developmental age, there is a progressive change in the morphology of the majority of axons from very simple (E38-42) to one in which many side branches are present (E43-48). Still later (E50-54), the majority of axons have a distinct arbor framework and fewer side branches. Finally (E57-P2), many axons with a dense terminal arbor, few or no side branches, and a smooth axon trunk can be found. $n=$ number of axons studied during each period.

the LGN, but also along the entire course of their main axon trunk. In contrast, after distinct layers of eye input emerge, by E57 and E63, axons are smooth along their main trunk, with a well-defined terminal arbor in contralateral layer A. This analysis suggests that as axons grow into the LGN, they initially elaborate side branches in LGN territory that ultimately is only occupied by afferents from the other eye.

In order to investigate this suggestion more directly, we devised a way to correlate the location of side branches on a given axon with the known global projection from one eye as revealed by anterograde tracing methods. To do this, animals to be studied received an intraocular injection of ${ }^{3} \mathrm{H}$-leucine in one eye, thereby establishing the location of the projection from that eye within the LGN. The next day in the same fetus retinogeniculate axons were labeled with HRP and reconstructed. After reconstructing a number of HRP-filled axons and locating all their side branches, LKB tritium-sensitive film was placed against the tissue sections, and the pattern of retinal projection from the injected eye was visualized autoradiographically. Autoradiographs of the labeling pattern in the LGN after eye injections are shown in Figure 13. The pattern at E53, a time when afferents from the two eyes have begun to segregate, is shown at the top. The pattern at E58, when afferents are nearly completely segregated, is shown at the bottom of Figure 13 .

We chose animals E53 and older for two reasons. One is that at these ages a substantial amount of segregation of eye input has already occurred within layers $A$ and $A 1$, as revealed in the autoradiographs (Fig. 13) following intraocular injections. The other is that the terminal branching pattern of individual HRPfilled axons is sufficiently well developed. Thus, identification with respect to eye of origin is possible on the basis of the location of the axon's terminal arbor with respect to the autoradiographic labeling pattern. This approach allowed us to identify axons and examine the relationship of their side branches to the labeled projection from the injected eye.

The results of this analysis are shown in Figure 14. In the top half of the figure, five axons identified as originating from the contralateral eye, based on the location of their terminal arborization within the inner third of the LGN, are shown in relationship to the autoradiographic labeling pattern from the ipsilateral eye (shaded area). Although only a few side branches are evident along the main axon trunk of each axon, owing to the maturity of the axons at these older ages, many of the side branches are unambiguously located in territory that belongs to the ipsilateral eye (shaded region).

The opposite case, in which the locations of axons likely to originate from the ipsilateral eye are correlated with the labeled projection pattern from the contralateral eye, is shown in Figure $14 B$. As can be seen, the distal tips of the terminal arbors of each axon extend upward into territory occupied by afferents from the contralateral eye (cross-hatching), and one axon is remarkable in that an entire long process extends upward for a considerable distance into layer $A$. In addition, several axons send branches into the contralaterally innervated zone of the future C-layers. It should be noted that the precise location of the border between layers $\mathrm{A}$ and $\mathrm{Al}$ cannot be determined at these ages because of the residual intermixing of inputs from the two eyes known to occur in the border zones (Shatz, 1983). The fact that the distal tips of presumptive ipsilateral eye axons are located in a region of the LGN receiving a heavy input from the contralateral (injected) eye is consistent with this previous finding.

In order to check the reliability of this approach, we examined several animals at F63 and P2, after segregation is complete and the eye-specific layers have formed. As expected, all of the axons examined at these ages had their terminal arborizations restricted to territory outside the radioactively labeled layers from the other eye. With rare exception, reconstructed axon trunks were completely smooth as they traversed layers innervated by the other eye.

These experiments indicate that during the period in which afferents from the two eyes are intermixed within the LGN, individual axons from one eye have side branches (and distal tips in the case of the ipsilateral eye axons) located in territories destined to be occupied by axons from the other eye. The subsequent disappearance of side branches and simultaneous elaboration of a restricted terminal arbor coincides with the appearance of eye-specific layers present by birth.

\section{Discussion}

In this study, the morphology of individual retinogeniculate axons at various stages during the prenatal development of the cat's visual system has been examined in order to gain a better understanding of how the separate eye-specific layers within the LGN develop from an initially intermixed pattern of afferent input. Using an in vitro method of filling fetal retinal axons with HRP, we found that segregation of eye inputs is correlated with two fundamental and simultaneous events at the level of axon morphology. One is the addition of new axon to form a restricted terminal arbor localized within the layer appropriate to the eye 


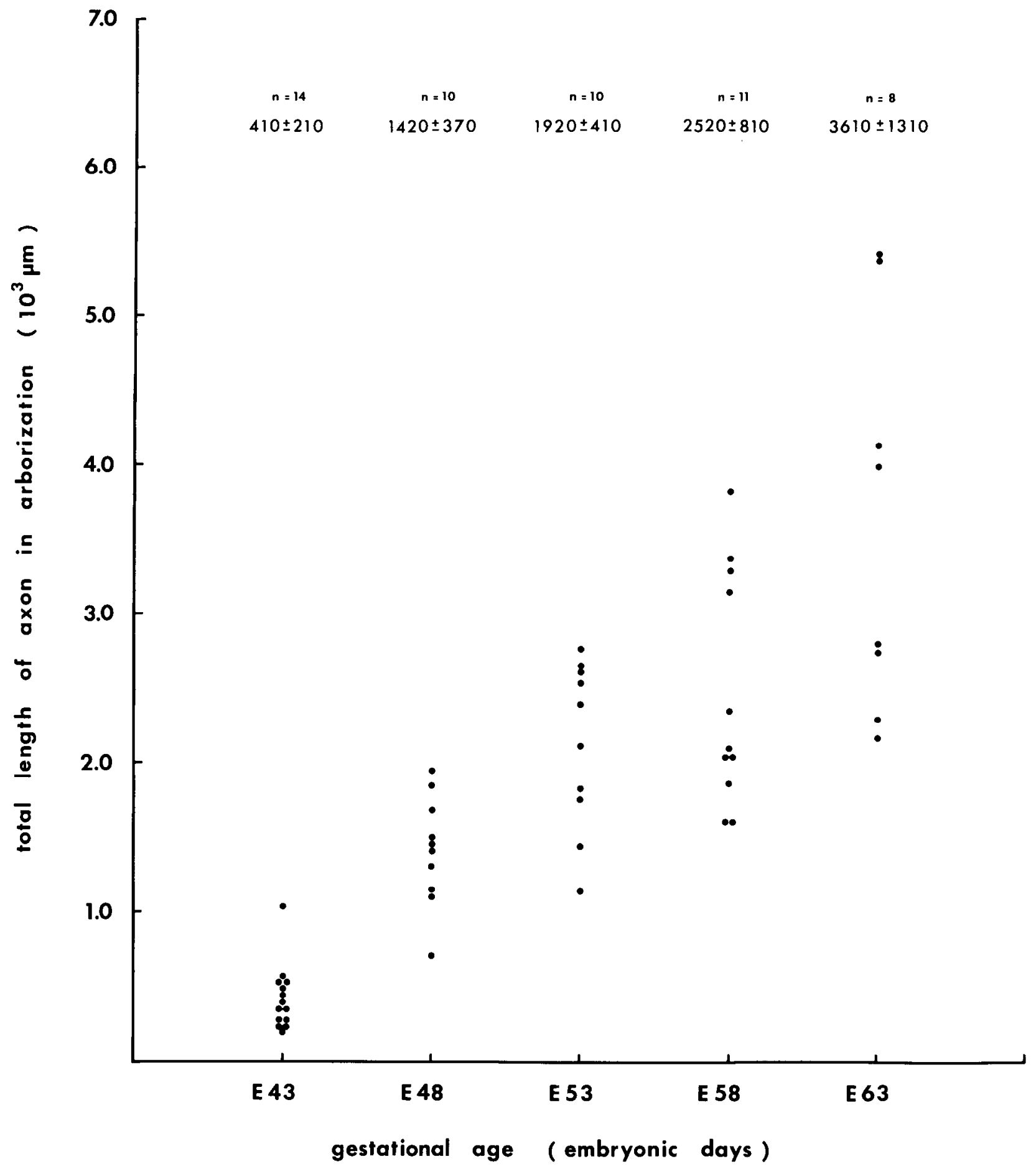

Figure 9. Graph showing the relationship between the total amount (length) of axon contributing to the terminal arbor and developmental age. Each black dot represents the measurement from one retinogeniculate axon. For each axon, all axon segments belonging to the terminal arborization were measured. For immature axons, all side branches were measured (the main axon trunk was not included). The number of axons measured and the average amount of axon making up the terminal arbor at each age are given at the top of the graph. Throughout prenatal development, there is roughly a linear relationship between the amount of axon added to the terminal arbor and increasing developmental age. For each age, all axons measured were from the same fetus; thus, the variation seen here is not the result of combining data from several animals.

of axon origin. The other event involves the remodeling of the branching pattern along the length of the main axon trunk so that the side branches present early on in certain regions of the LGN are eliminated and the main axon trunk becomes smooth and devoid of processes. We believe that this selective retraction of short side branches, coupled with the continued elaboration and growth of axon terminal arbors within a fixed framework, leads simultaneously to a reduction in the amount of territory shared by the two eyes and to the formation of eye-specific layers.

The sequence of developmental events outlined above is based on several lines of evidence. One of the most important involves the contention that the side branches indeed represent a morphological substrate for the intermixing of inputs from the two eyes seen with anterograde tracing methods following intraocular injections (Shatz, 1983). Evidence for this conclusion comes 


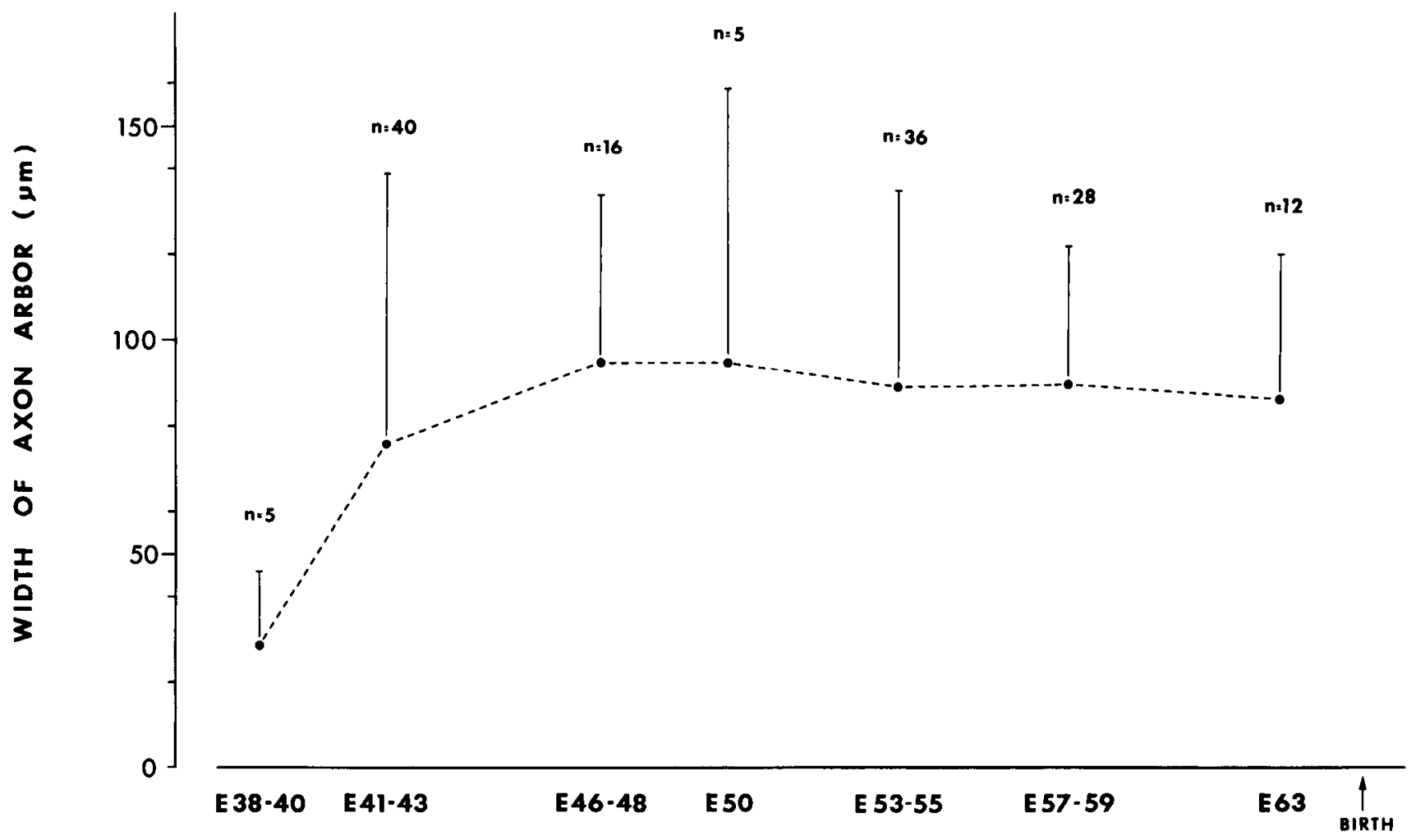

\section{GESTATIONAL AGE}

Figure 10. Graph showing the relationship between the width of axon arbor with developmental age. For each axon, the total mediolateral extent of its branches, or the width of its terminal arbor, was measured and pooled into a given age group. The number of axons measured for each age group is shown above. The average width is indicated by the black dot, and the vertical bars represent the SD for a given group. With increasing developmental age, the width of axon arbors shows an increase, which then reaches a plateau at just a little under 100 $\mu \mathrm{m}$ by about E46-48.

from the following observations. First, when retinal axons were examined during the period when input from the two eyes is known to be intermixed, they were found to be very simple with a sparse branching pattern comprised mainly of short side branches. Second, we demonstrated that side branches are given off by axons as they course through regions of the nucleus that are destined to be innervated exclusively by input from the other eye in the adult. Third, the side branches are transient and are

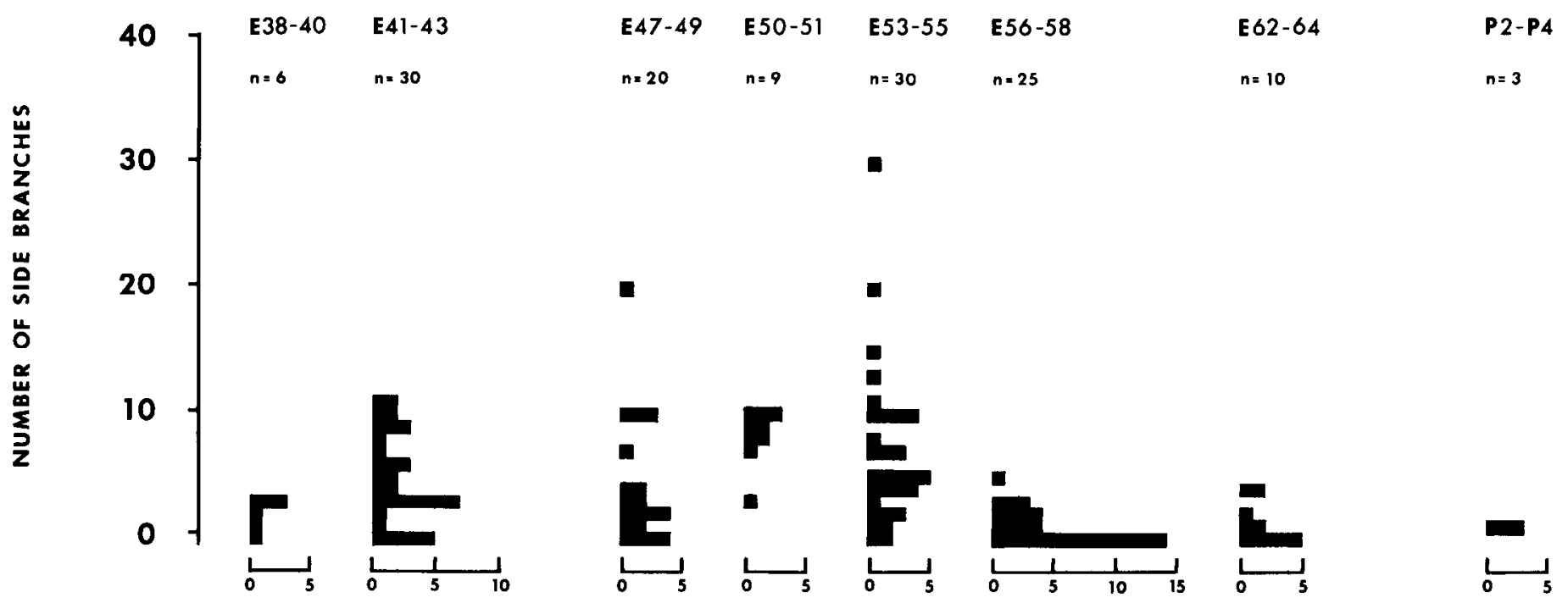

Figure 11. Graph showing the number of side branches on axons during development. For each axon in an age group, the number of side branches was counted and marked at the correct location on the $y$-axis with a black square. The number of axons analyzed in this manner for each age group is shown at the top of the graph. During the period of intermixing (E38-55), the vast majority of axons have side branches. With the formation of eye-specific layers (E56-P4), many fewer side branches are found on the main trunks of axons. 


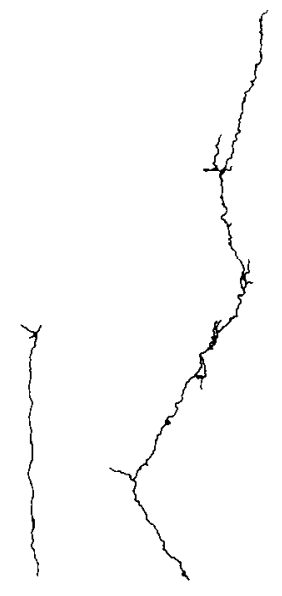

E38

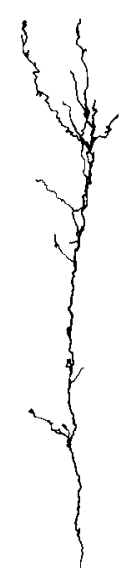

E43

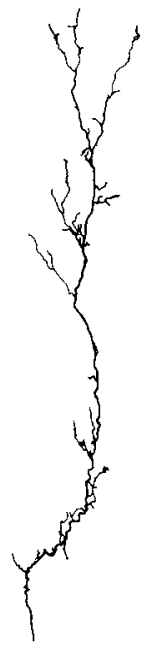

E48

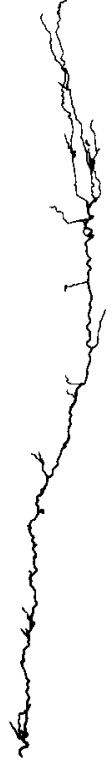

E53

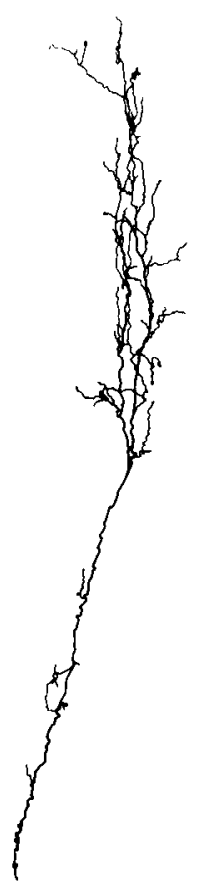

E53

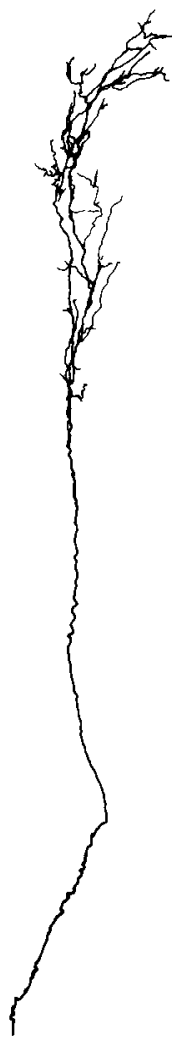

E57

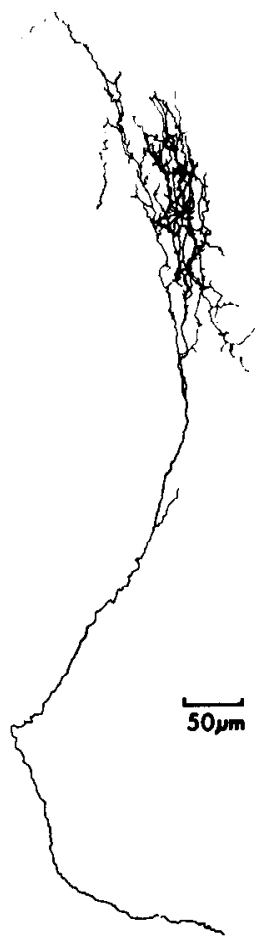

E63
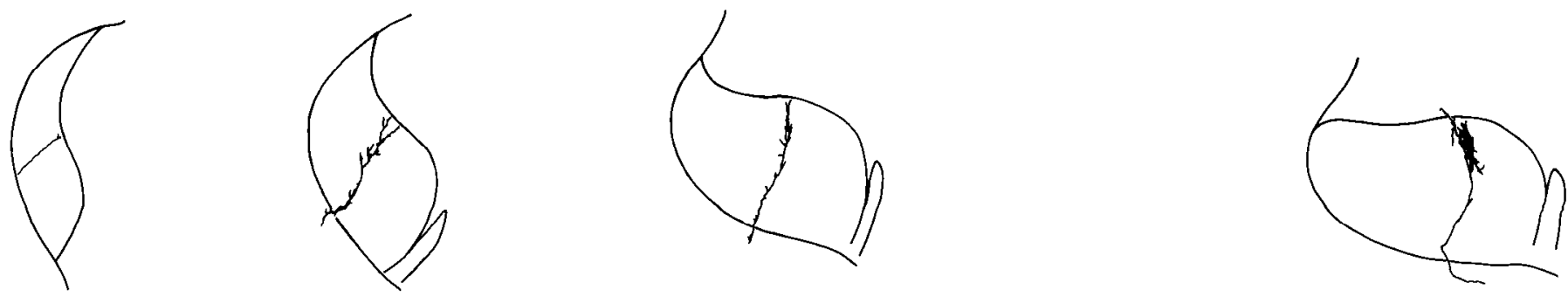

Figure 12. Diagram showing the relationship between side branches on axons likely to originate from the contralateral eye as they course through regions occupied by ipsilateral afferents during development. Contralateral retinogeniculate axons from various fetal ages are shown in relationship to the borders of the LGN. The reconstructions of four of the axons have been superimposed onto the drawings of the LGN below. Since the axons were reconstructed from multiple sections, the relationship between the lower parts of each axon and the optic tract is not accurate with respect to the outline of the LGN shown in the single section here. During the time when input from the contralateral and ipsilateral eyes are intermixed in the middle regions of the nucleus (E42-53), contralateral axons, as they course through this region, give off side branches. After segregation is nearly complete and when eye-specific layers have formed (E57-63), contralateral axons no longer have side branches in the middle regions of the nuclcus, which arc now exclusively occupied by afferents from the ipsilateral eye.

not present on adult axons or even on axons during prenatal life after the adultlike pattern of segregated layers has formed. Finally, the time course of appearance and subsequent loss of side branches from the axon trunks parallels the time course of the initial intermixing of inputs and subsequent reduction in the territory shared by the two eyes as determined by intraocular injection experiments (Shatz, 1983). In sum, this evidence suggests that the side branches are an important substrate, allowing inputs from the two eyes to interact during development. If so, it would be of great interest to know whether the side branches actually form synapses with LGN neurons.

A summary diagram of the events that may underlie the prenatal devclopment of cyc-spccific layers in the cat's LGN is shown in Figure 15. Row A shows the outline of the LGN at four developmental ages. At each age, the territory in which the projections from the two eyes are intermixed, as determined from intraocular injections of tracers (Shatz, 1983), is indicated by gray shading. With time, the amount of territory shared by the two eyes decreases. Row B shows schematically, at each corresponding age, the typical branching patterns of retinogeniculate axons found in the present study. In each case, one axon from the contralateral eye and one from the ipsilateral eye are depicted. Sidc branches are characteristically found on retinal axons during the period in which contralateral and ipsilateral projections are intermixed (E46, E53). We propose that the gradual elimination of side branches along the main axon trunk, coupled with growth of the terminal arbor, leads to a reduction in intermixing of input and the onset of segregation of input from the two eyes (E53). Finally, the further elaboration and growth of the terminal arbors leads to the formation of the 

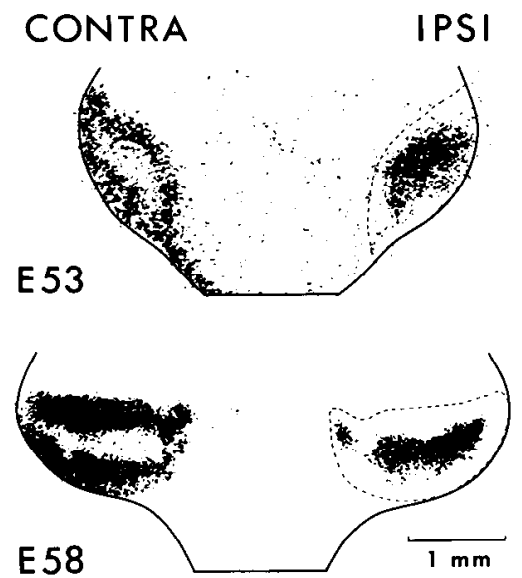

Figure 13. Autoradiographic labeling pattern in the LGN as seen on LKB film after an intraocular injection of ${ }^{3} \mathrm{H}$-leucine in an E53 and an E58 fetus.

adultike pattern of eye-specific layers of afferent input (E63). Even at birth retinogeniculate axons are by no means mature, since a good deal of additional growth and maturation occurs during the first few months of postnatal life (Mason, 1982; Sur et al., 1984). However, it is worth noting that the segregation of eye input is complete at these ages; hence, growth is restricted to the terminal arbor itself.
Of course, our results do not imply that the retraction of transient side branches is the only means whereby a reduction in the intermixing of inputs from the two cyes can occur. Another possibility is reduction due to cell death. Cell death has been proposed to underly the development of eye-specific layers in the primate retinogeniculate system (Rakic and Riley, 1983a, b). This suggestion has been made because in primates, as well as in many other species (including the cat), a massive loss of axons is known to occur in the optic nerve (Crespo et al., 1984; Lam et al., 1982; Ng and Stone, 1982; Perry et al., 1983; Rakic and Riley, 1983a; Williams et al., 1983) during the same period in which segregation of eye input occurs in visual target structures such as the LGN and the superior colliculus (Bunt et al., 1983; Rakic, 1977; Shatz, 1983; So et al., 1978; Williams and Chalupa, 1982). To be consistent with the results reported here, cell death might operate in the following way to give rise to segregated layers of eye input: During the time when inputs are intermixed, axons from one eye might be divided into those that are correctly located in regions of the nucleus destined to belong to that eye, and those that project incorrectly to territory destined to be occupied by the other eye. The reduction in intermixing might then be accomplished if all the axons projecting to inappropriate territories die off. In view of the results from the present study indicating that all axons initially have side branches that are subsequently retracted, we consider it likely that remodeling of the branching pattern (by elimination of inappropriately placed side branches) is responsible in large part for the segregation of retinal input into eye-specific layers
Figure 14. Reconstructions of retinogeniculate afferents from E53 to E58 showing the relationship between axons with side branches and the LGN territories destined to be occupied by the other eye. The reconstructions of retinogeniculate axons likely to originate from one eye (see text) have been superimposed onto the regions of the nucleus occupied by afferents from the other eye, as determined by autoradiographic methods. $A$, Five axons likely to be from the contralateral eye and their side branches are shown in relationship to the region of the nucleus destined to be occupied by afferents from the ipsilateral eye (shad$e d$ areas). $B$, Five axons thought to be from the ipsilateral eye with processes extending into regions of the nucleus occupied by afferents from the contralateral eye. Note that the broken lines in $A$ and $B$ only indicate the limits of autoradiographic label and not the borders between adjacent layers, since, even at these ages, inputs from the two eyes are still intermixed along border zones. Also note that the full extent of autoradiographic labeling in layer $A$ of $B$ has not been shown. See text for further details.

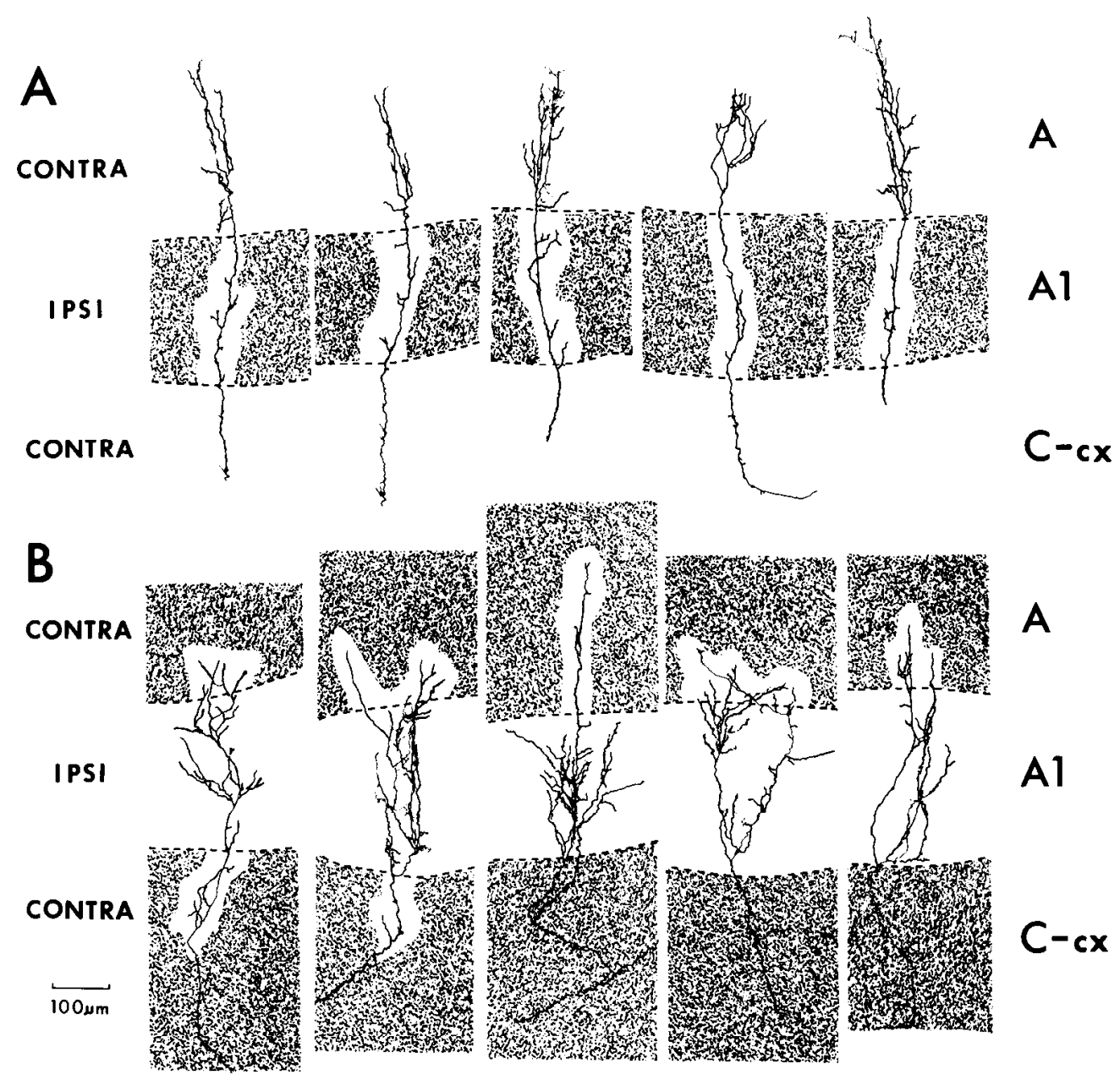


during prenatal development. However, since we were unable to obtain adequate filling of retinogeniculate arbors by labeling axons in the optic nerve, we cannot exclude the possibility that some axons from one eye may erroneously form restricted terminal arbors in territory belonging to the other eye and that their elimination also contributes to the segregation of eye input. The exact relationship between cell death and the development of eye-specific layers in the LGN would be better understood if it were known whether the optic axons to be eliminated actually innervate the LGN during development.

It is quite possible that cell death may play only a minor role in segregation of eye input but a major role in other aspects of the development of the retinogeniculate projection. For example, it is known that cell death contributes to the elimination of topographic errors in the retinocollicular pathway in rodents (Fawcett et al., 1984; Insausti et al., 1984; Jeffery and Perry, 1981). Thus, cell death may serve principally to refine topographic connections in retinal projections rather than to form eye-specific layers in the LGN. Another possible role for cell death comes from the observations that the death of retinal ganglion cells during prenatal development in the cat occurs preferentially at the periphery of the retina (Kliot and Shatz, 1982; Sengelaub and Finlay, 1982; Stone et al., 1982). Thus, cell death could be part of the process by which a central-toperipheral gradient in retinal ganglion cell density is generated during prenatal development. Further evidence supporting these suggestions is given elsewhere (Sretavan and Shatz, in press).

\section{Comparison with other species}

While the pattern and time course of segregation of eye input in the LGN of animals with less binocular vision (hence a smaller ipsilateral projection) appears somewhat different, it is very likely that the underlying events share much in common. In cats, inputs from the contralateral and ipsilateral eyes are initially intermixed mainly in the region of the nucleus representing the binocular segment. (The binocular segment is that portion of the LGN in which inputs from the two eyes subserving the same visual field coordinates are in register in adjacent layers.) In both hamsters and ferrets, the initial territory shared by both eyes includes not only the future binocular regions of the LGN, but also a large part of the monocular segment, which, in the adult, belongs exclusively to the contralateral eye (Card-Linden et al., 1981; Frost et al., 1979; So et al., 1978, 1984). (This situation may also occur in the cat, but because the ipsilateral projection is large, invasion of the monocular segment may not be as apparent.) As a consequence, not only must afferents from the ipsilateral eye segregate from their topographically matched contralateral counterparts in the future region of the binocular segment, but also the ipsilateral afferents must be removed from the future monocular region that is only represented in the contralateral eye. Within the binocular segment, we imagine that retinogeniculate axons in other species go through the same sequence of morphological changes as those described here in the cat (see Fig. 15). (Inspection of HRP-filled axons in some of our own material from newborn ferrets is consistent with this suggestion.) In contrast, the elimination of the ipsilateral projection to the monocular segment cannot be due simply to the retraction of side branches. Rather, whole axons must be removed, and this could be accomplished by any or all of the following: cell death, complete retraction of axon collaterals from the LGN, and large-scale restructuring or movement of axon terminal arbors. Thus, it may be that while cell death, collateral elimination, and axon terminal restructuring and movement contribute to the development of the segregated pattern of eye input in all species, the relative contributions of each may vary.

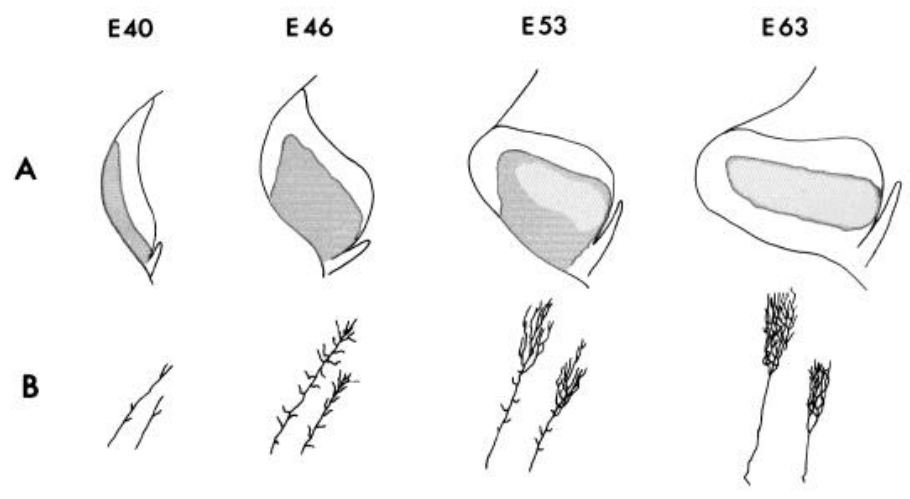

Figure 15. Summary diagram illustrating the morphological changes in single retinogeniculate axons that accompany the formation of eyespecific layers in the cat's LGN.

\section{Comparison with development of segregated input to the visual cortex}

The strategy of forming the adult pattern of connections from an intermixed state in the visual cortex appears to differ from that used in the formation of segregated layers of eye input in the LGN during prenatal development. Preliminary data suggest that at the cortical level a good deal of overgrowth followed by extensive retraction may occur (Florence and Casagrande, 1984; LeVay and Stryker, 1978). In contrast, retinogeniculate axons retract only a limited number of short side branches along the axon trunk correlated with the reduction in intermixing of eye input, suggesting that the decision-making process leading to the segregation of eye input at the LGN is an extremely conservative and economical one, since axons do not retract whole arbors to achieve the segregated state. Indeed, the elimination of side branches during the period of segregation is accompanied simultaneously by the elaboration of an extensive and appropriately located terminal arbor. Thus, while evidence suggests that both retinogeniculate and geniculocortical axons undergo retraction of axonal processes, followed by further elaboration of a terminal arbor, additional study at the cortical level is required to determine whether the relative amount of initial overgrowth and subsequent retraction of the two types of axons differs.

\section{Side branches and binocular interactions}

In this study, we have shown that one fundamental event accompanying the formation of eye-specific layers from an intermixed state in the retinogeniculate system is the selective retraction of side branches along axons from certain regions of the nucleus, as axons from the other eye develop terminal arbors in those regions. The development of retinogeniculate axons can now be added to an increasing number of examples in which it can be demonstrated anatomically that the adult pattern of axon arborization arises from a remodeling of axons (including retraction) during CNS development. These include the development of callosal connections (Innocenti, 1981; Ivy and Killackey, 1982; O'Leary et al., 1981), the development of connections within the chick auditory system (Jackson and Parks, 1982; Jhaveri and Morest, 1982; Young and Rubel, 1984), and, as discussed above, the development of geniculocortical axons (LeVay and Stryker, 1978).

Much of our current understanding of the possible mechanisms underlying the anatomical rearrangement of connections during development comes from studies of systems in which the formation of the adult pattern of connections can be assessed 
physiologically. Accumulated evidence from studies of many different systems, including the cat's retinogeniculate system, indicates that during the period in which the mature pattern of connectivity emerges from an initially immature pattern, the presynaptic inputs are capable of synaptic function (for review, see Jackson and Parks, 1982; Johnson and Purves, 1981; Purves and Lichtman, 1980; Shatz and Kirkwood, 1984). The results of these studies suggest that activity itself may play an important role in producing the transition to a mature set of connections, a suggestion that has been verified recently in a number of different systems. For instance, at the mammalian neuromuscular junction (Thompson, 1983; Thompson et al., 1979) and in the mammalian visual system (Stryker, 1981; Stryker and Harris, in press; Stryker and Strickland, 1984), blocking activity with tetrodotoxin or altering the pattern of activity with electrical stimulation alters the time course of maturation to the adult state.

If activity is to play a role in the prenatal development of the cat's retinogeniculate system, then during the period of intermixing of eye inputs, LGN neurons should receive functional inputs in an immature pattern. This is the case, since individual LGN neurons can be driven synaptically by electrical stimulation of both optic nerves (Shatz and Kirkwood, 1984). The question therefore arises as to what is the anatomical substrate for these synaptic interactions. The results from our present study suggest that the side branches found along axons during this period could supply at least a part of the immature functional inputs to LGN neurons. In this regard, it is noteworthy that the disappearance of the side branches by birth is also correlated with a change in the synaptic physiology of the retinogeniculate projection to a more mature state in which LGN neurons can only be driven monosynaptically by stimulation of one optic nerve (Lindström, 1982; Shatz and Kirkwood, 1984). Direct evidence that side branches participate in synaptic relations is currently unavailable, since we have not yet been able to obtain adequate fixation of our HRP-labeled in vitro preparations for electron microscopy. However, in the development of the hamster retinogeniculate system, transient synapses from the ipsilateral eye have been found in territory ultimately occupied exclusively by the contralateral eye (Campbell et al., 1984). Although these synapses could be supplied by side branches, it is equally possible that many are also en passant along the length of the main axon trunk. We consider both of these possibilities likely from our own EM studies in which retinogeniculate axons have been labeled by the anterograde transport of HRP from an eye injection (Shatz and Siegel, unpublished observations). Thus, it may be that binocular interactions known to occur during the segregation of eye input in the cat's retinogeniculate system are mediated through snyaptic connections formed by side branches given off by axons as they coursc through territory temporarily shared by the two sets of afferents.

\section{References}

Adams, J. C. (1981) Heavy metal intensification of DAB-based HRP reaction product. J. Histochem. Cytochem. 29: 775

Bowling, D. B. (1984) Differences in the timing and sensitivity of responses from cells across single layers of the lateral geniculate nucleus in the cat. Soc. Neurosci. Abstr. 10: 296.

Bowling, D. B., and C. R. Michael (1980) Projection patterns of single physiologically characterized optic tract fibers in the cat. Nature 286 . 899-902.

Bunt, S. M., R. D. Lund, and P. W. Land (1983) Prenatal development of the optic projection in albino and hooded rats. Dev. Brain Res. 6: 149-168.

Calvacante, L. A., and C. E. Rocha-Miranda (1978) Postnatal development of retinogeniculate, retinopretectal and retinotectal projections in the opposum. Brain Res. 146: 231-248.

Campbell, G., K.-F. So, and A. R. Lieberman (1984) Normal postnatal development of retinogeniculate axons and terminals and identifi- cation of inappropriately located transient synapses. Electron microscope studies of HRP labeled retinal axons in the hamster. Neuroscience 13: 743-759.

Card-Linden, D., R. W. Guillery, and J. Cucchiaro (1981) The dorsal lateral geniculate nucleus of the normal ferret and its postnatal development. J. Comp. Neurol. 203: 189-211.

Crespo, D., D. D. M. O'Leary, and W. M. Cowan (1984) Reduction of optic nerve axons during the postnatal development of the albino rat. Soc. Neurosci. Abstr. 10: 464.

Fawcett, J. W., D. D. M. O'Leary, and W. M. Cowan (1984) Activity and the control of ganglion cell death in the rat retina. Proc. Natl. Acad. Sci. USA 81: 5589-5593.

Florence, S. L., and V. A. Casagrande (1984) Postnatal development of geniculostriate axons in Galago. Soc. Neurosci. Abstr. 10: 142.

Frost, D. O., K.-F. So, and G. E. Schneider (1979) Postnatal development of retinal projections in Syrian hamsters: A study using autoradiographic and anterograde degeneration techniques. Neuroscience 4: 1649-1677.

Guillery, R. W. (1970) The laminar distribution of retinal fibers in the dorsal lateral geniculate nucleus of the cat: A new interpretation. J. Comp. Neurol. 138: 339-368.

Illing, R. B., and H. Wässle (1981) The retinal projection to the thalamus in the cat: $A$ quantitative investigation and a comparison with the retinotectal pathway. J. Comp. Neurol. 202: 256-286.

Innocenti, G. M. (1981) Growth and reshaping of axons in the establishment of visual callosal axons. Science 212: 824-827.

Insausti, R., C. Blakemore, and W. M. Cowan (1984) Ganglion cell death during development of ipsilateral retino-collicular projection in golden hamster. Nature 308: 362-365.

Ivy, G. O., and H. P. Killackey (1982) Ontogenetic changes in the projections of neocortical neurons. J. Neurosci. 2: 735-742.

Jackson, H., and T. N. Parks (1982) Functional synapse elimination in the developing avian cochlear nucleus with simultaneous reduction in cochlear nerve axon branching. J. Neurosci. 2: 1736-1743

Jeffery, G., and V. H. Perry (1981) Evidence for ganglion cell death during development of the ipsilateral retinal projection in the rat. Dev. Brain Res. 2: 176-180.

Jhaveri, S., and D. K. Morest (1982) Sequential alterations of neuronal architecture in nucleus magnocellularis of the developing chicken: $\mathrm{A}$ Golgi study. Neuroscience 7: 837-853

Johnson, D. A., and D. Purves (1981) Postnatal reduction of neural unit size in the rabbit ciliary ganglion. J. Physiol. (Lond.) $318: 143-$ 159.

Kalil, R. (1978) Development of the dorsal lateral geniculate nucleus in the cat. J. Comp. Neurol. 182: 265-292.

Kliot, M., and C. J. Shatz (1982) Genesis of different retinal ganglion cell types in the cat. Soc. Neurosci. Abstr. 8: 815.

Lam, K., J. Sefton, and M. R. Bennett (1982) Loss of axons from the optic nerve of the rat during early postnatal development. Dev. Brain Res. 3: 487-491.

LeVay, S., and M. P. Stryker (1978) The development of ocular dominance columns in the cat. In Aspects of Developmental Neurobiology, J. Ferendelli, ed., pp. 83-98, Society for Neuroscience, Bethesda, MD.

LeVay, S., M. P. Siryker, and C. J. Shatz (1978) Ocular dominance columns and their development in layer IV of the cat's visual cortex: A quantitative study. J. Comp. Neurol. 179: 223-244.

Lindström, S. J. (1982) Synaptic organization of inhibitory pathways to principal cells in the lateral geniculate nucleus of the cat. Brain Res. 234: 447-453.

Mason, C. A. (1982) Development of terminal arbors of retinogeniculate axons in the kitten-I. Light microscopical observations. Neuroscience 7: 541-559.

$\mathrm{Ng}, \mathrm{A}$., and J. Stone (1982) The optic nerve of the cat: Appearance and loss of axons during normal development. Dev. Brain Res. 5: 263-271.

O'Leary, D. D. M., B. B. Stanfield, and W. M. Cowan (1981) Evidence that the early postnatal restriction of the cells of origin of the callosal projection is due to elimination of axonal collaterals rather than to the death of neurons. Dev. Brain Res. 1: 607-617.

Perry, V. H., Z. Henderson, and R. Linden (1983) Postnatal changes in retinal ganglion cell and optic axon populations in the pigmented rat. J. Comp. Neurol. 219: 356-368.

Purves, D., and J. W. Lichtman (1980) Elimination of synapses in the developing nervous system. Science $210: 153-157$.

Rakic, P. (1977) Prenatal development of the visual system in rhesus monkey. Phil. Trans. R. Soc. London [Biol.] 278: 245-260. 
Rakic, P., and K. P. Riley (1983a) Overproduction and elimination of retinal axons in the fetal rhesus monkey. Science 219: 1441-1444.

Rakic, P., and K. P. Riley (1983b) Regulation of axon number in primate optic nerve by prenatal binocular competition. Nature 305 : 135-137.

Rodiek, R. W. (1979) Visual pathways. Annu. Rev. Neurosci. 2: 193226.

Sanderson, K. J. (1971) The projection of the visual field to the lateral geniculate and medial interlaminar nuclei in the cat. J. Comp. Neurol. 143: $101-118$.

Sanderson, K. J., P. G. Dixon, and L. P. Pearson (1982) Postnatal development of retinal projections in the brushtailed possum, Trichosurus vulpecula. Dev. Brain Res. 5: 161-180.

Sengelaub, D. R., and B. L. Finlay (1982) Cell death in the mammalian visual system during normal development: I. Retinal ganglion cells. J. Comp. Neurol. 204: 311-317.

Shatz, C. J. (1983) The prenatal development of the cat's retinogeniculate pathway. J. Neurosci. 3: 482-499.

Shatz, C. J., and P. Kirkwood (1984) Prenatal development of functional connections in the cat's retinogeniculate pathway. J. Neurosci. 4: 1378-1397.

So, K.-F., G. E. Schneider, and D. O. Frost (1978) Postnatal development of retinal projections to the lateral geniculate body in Syrian hamsters. Brain Res. 142: 343-352.

So, K.-F., H. H. Woo, and L. S. Jen (1984) The normal and abnormal postnatal development of retinogeniculate projections in golden hamsters: An anterograde horseradish peroxidase tracing study. Dev. Brain Res. 12: 191-205.

Sretavan, D. W., and C. J. Shatz (1984) Prenatal development of individual retinogeniculate axons during the period of segregation. Nature 308: 845-848.

Sretavan, D. W., and C. J. Shatz (in press) Prenatal development of retinogeniculate axon arbors in the absence of binocular interactions. J. Neurosci.

Stone, J., D. H. Rapaport, R. W. Williams, and L. Chalupa (1982) Uniformity of cell distribution in the ganglion cell layer of prenatal cat retina: Implications for mechanisms of retinal development. Dev. Brain Res. 2: 231-242.
Stryker, M. P. (1981) Late segregation of the geniculate afferents to the cat's visual cortex after recovery from binocular impulse blockade. Soc. Neurosci. Abstr. 7: 842.

Stryker, M. P., and W. Harris (in press) Binocular impulse blockade prevents the formation of ocular dominance columns in cat visual cortex. J. Neurosci.

Stryker, M. P., and S. L. Strickland (1984) Physiological segregation of ocular dominance columns depends on the pattern of afferent electrical activity. Invest. Ophthalmol. Vis. Sci. (Suppl.) 25: 278.

Sur, M., and S. M. Sherman (1982) Retinogeniculate terminations in cats. Morphological differences between $\mathrm{X}$ - and $\mathrm{Y}$-cell axons. Science 218: 389-391.

Sur, M., R. Weller, and S. M. Sherman (1984) Development of Xand $\mathrm{Y}$-cell retinogeniculate terminations in kittens. Nature 310:246248.

Thompson, W. (1983) Synapse elimination in neonatal rat muscle is sensitive to pattern of muscle use. Nature 302: 614-616.

Thompson, W., D. P. Kuffler, and J. K. S. Jansen (1979) The effect of prolonged, reversible block of nerve impulses on the elimination of polyneuronal innervation of new-born rat skeletal muscle fibers. Neuroscience 4: 271-281.

Walsh, C., E. H. Polley, T. L. Hickey, and R. W. Guillery (1983) Generation of cat retinal ganglion cclls in relation to central pathways. Nature 302: 611-614.

Wässle, H. (1982) Morphological types and central projections of ganglion cells in the cat retina. In Progress in Retinal Research, N. Osborne and G. Chader, eds., pp. 125-152, Pergamon, New York.

Williams, R. W., and L. M. Chalupa (1982) Prenatal development of retinocollicular projection in the cat: An autoradiographic tracer transport study. J. Neurosci. 2: 604-622.

Williams, R. W., M. J. Bastiani, and L. M. Chalupa (1983) Addition and attrition of axons within the optic nerve during fetal development: Appearance of growth cones and necrotic axons. Invest. Ophthalmol. Vis. Sci. (Suppl.) 24: 8 .

Young, S. R, and E. W. Rubel (1984) The embryonic development of axonal arborizations in nucleus laminaris of the chick auditory system. Soc. Neurosci. Abstr. 10: 41 . 